\title{
Nuclear Energy R\&D Imperative 3: Enable a Transition Away from Fossil Fuels in the Transportation and Industrial Sectors
}

March 2010

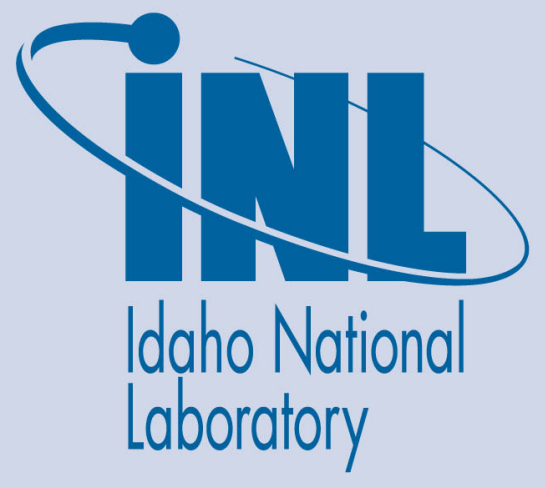

The INL is a U.S. Department of Energy National Laboratory operated by Battelle Energy Alliance 
INL/EXT-09-17525

\section{Nuclear Energy R\&D Imperative 3: Enable a Transition Away from Fossil Fuels in the Transportation and Industrial Sectors}

March 2010

Idaho National Laboratory
Idaho Falls, Idaho 83415

http://www.inl.gov

Prepared for the

U.S. Department of Energy

Office of Nuclear Energy

Under DOE Idaho Operations Office

Contract DE-AC07-05ID14517 


\section{Nuclear Energy R\&D Imperative 3: Enable a Transition Away from Fossil Fuels in the Transportation and Industrial Sectors}

March 2010

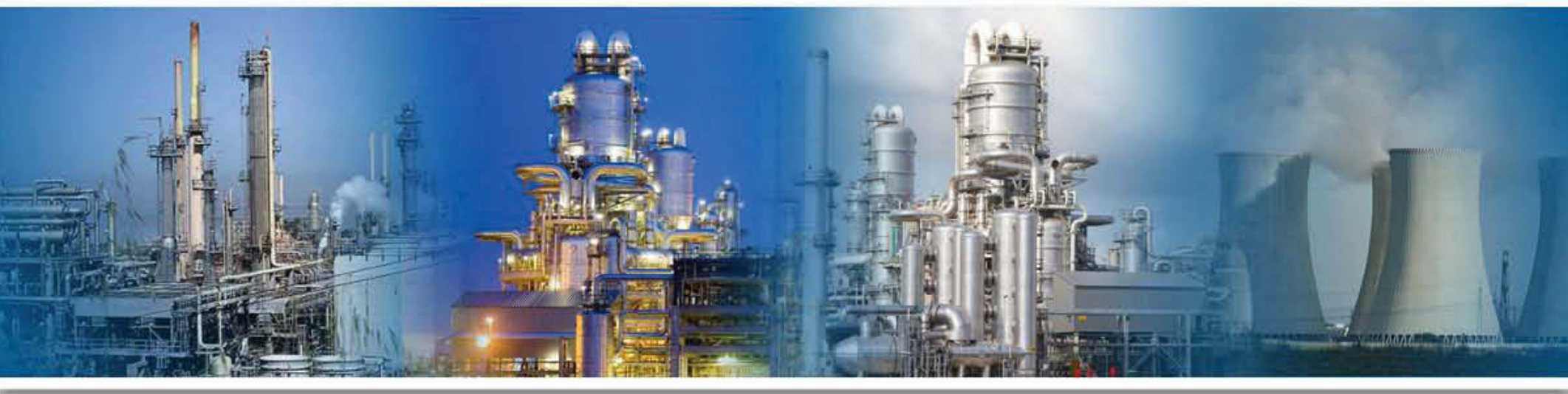




\section{DISCLAIMER}

This information was prepared as an account of work sponsored by an agency of the U.S. Government. Neither the U.S. Government nor any agency thereof, nor any of their employees, makes any warranty, express or implied, or assumes any legal liability or responsibility for the accuracy, completeness, or usefulness of any information, apparatus, product, or process disclosed, or represents that its use would not infringe privately owned rights. References herein to any specific commercial product, process, or service by trade name, trademark, manufacturer, or otherwise, does not necessarily constitute or imply its endorsement, recommendation, or favoring by the U.S. Government or any agency thereof. The views and opinions of authors expressed herein do not necessarily state or reflect those of the U.S. Government or any agency thereof. 


\section{SUMMARY}

As described in the Department of Energy Office of Nuclear Energy's Nuclear Energy R\&D Roadmap, nuclear energy can play a significant role in supplying energy for a growing economy while reducing both our dependence on foreign energy supplies and emissions from the burning of fossil fuels. The industrial and transportation sectors are responsible for more than half of the greenhouse gas emissions in the U.S., and imported oil supplies $70 \%$ of the energy used in the transportation sector. It is therefore important to examine the various ways nuclear energy can facilitate a transition away from fossil fuels to secure environmentally sustainable production and use of energy in the transportation and manufacturing industry sectors. Imperative 3 of the Nuclear Energy R\&D Roadmap, entitled "Enable a Transition Away from Fossil Fuels by Producing Process Heat for use in the Transportation and Industrial Sectors", addresses this need. This document presents an Implementation Plan for R\&D efforts related to this imperative.

The expanded use of nuclear energy beyond the electrical grid will contribute significantly to overcoming the three inter-linked energy challenges facing U.S. industry: the rising and volatile prices for premium fossil fuels such as oil and natural gas, dependence on foreign sources for these fuels, and the risks of climate change resulting from carbon emissions. Nuclear energy could be used in the industrial and transportation sectors to:

- Generate high temperature process heat and electricity to serve industrial needs including the production of chemical feedstocks for use in manufacturing premium fuels and fertilizer products,

- Produce hydrogen for industrial processes and transportation fuels, and

- Provide clean water for human consumption by desalination and promote wastewater treatment using low-grade nuclear heat as a useful additional benefit.

Opening new avenues for nuclear energy will significantly enhance our nation's energy security through more effective utilization of our country's resources while simultaneously providing economic stability and growth (through predictable energy prices and high value jobs), in an environmentally sustainable and secure manner (through lower land and water use, and decreased byproduct emissions). The reduction in imported oil will also increase the retention of wealth within the U.S. economy while still supporting economic growth. Nuclear energy is the only non-fossil fuel that has been demonstrated to reliably supply energy for a growing industrial economy.

Process heat applications cover a wide range of temperature needs. Low temperature applications can be achieved using LWR technologies that are covered in Imperatives 1 and 2. For higher temperature industrial applications, advanced reactors are required. The focus of Imperative 3 is on the R\&D required to develop viable commercial nuclear heat sources in the range of 500 to $900^{\circ} \mathrm{C}$, substantially above the 300 to $325^{\circ} \mathrm{C}$ outlet temperatures of light water reactors. Achieving these higher outlet temperatures requires the use of alternative reactor coolants such as gas, liquid metal, or liquid salt. It is possible to achieve outlet temperatures over $500^{\circ} \mathrm{C}$ with liquid metal coolants and over $900^{\circ} \mathrm{C}$ with helium or liquid salt coolants.

The Department of Energy has active programs pursuing liquid metal and gas-cooled reactors. The sodium-cooled and helium-cooled reactors were identified as priorities in the U.S. Generation IV Fast Reactor Strategy Report, December 2006, and in the U.S. Generation IV Implementation Strategy, September 2003. Of these, the gas-cooled reactor technology has the most near-term promise of meeting the needs of industry. The Next Generation Nuclear Plant project, administered by the Office of Nuclear Energy, is focused on gas-cooled reactor technology that is optimized for industrial use. The Next Generation Nuclear Plant is a high temperature gas-cooled reactor that is jointly being developed by the Department of Energy and industry. The Next Generation Nuclear Plant high temperature gas-cooled reactor is being designed for a 750 to $800^{\circ} \mathrm{C}$ outlet temperature, a level that meets most of the process 
heat needs of industry, and that is readily achievable on an expedited schedule. The high temperature gas-cooled reactor features a high degree of inherent passive safety, even in beyond design basis events, resulting in no significant fission product release from the core. This characteristic is very important in the licensing of such a reactor that would be collocated with industrial installations. The deployment of the first-of-a-kind helium cooled gas reactor through the Next Generation Nuclear Plant Project will be a major accomplishment toward commercialization of the technology. In the longer term, other options such as a liquid-salt-cooled reactor may be feasible.

The objectives/goals for Imperative 3 are:

- Use and expand existing nuclear energy technologies in a cost-effective and reliable manner to enable a reduction of emissions of greenhouse gases from the transportation and industrial sectors.

- Develop and qualify the technologies needed to enable reactors to provide process heat for a range of potential end users, including research on high burn up fuels and advanced materials necessary to achieve economical and efficient reactor systems with very high outlet temperatures.

- Develop interfacing heat transport, energy conversion, and hydrogen technologies that serve the reactor end user interface for the industrial and transportation sectors.

- Establish the basis for licensing reactors that enable high temperature process heat produced from nuclear energy to be delivered to industrial end users.

- Assist industry in the design, licensing, and construction of a demonstration nuclear heat source as part of the Next Generation Nuclear Plant project.

- Evaluate the economics and environmental characteristics of coupling a nuclear energy source to industrial applications to optimize deployment scenarios and establish credible business cases.

To meet these strategic goals, strong focus on the needs of the end user is required. The technologies developed and deployed must economically meet the needs on a time scale that allows nuclear energy to substantially penetrate these sectors over the coming decades. The research development and demonstration activities needed to execute this strategy are organized into three major pathways:

- Nuclear heat source: gas-cooled reactor fuel, graphite, high temperature materials and improved computational methods to support, in the near term, the Next Generation Nuclear Plant Project, and in the longer term, to support other advanced reactor concepts for use as a nuclear heat source.

- Reactor-industrial end-user interface development and integration: heat transport and system integration, hydrogen production, feedstock extraction and processing for hybrid energy industrial park applications, and byproduct management.

- Regulatory approach, system economics, and business case: system economic and environmental assessments upon which more credible business cases and technology-independent and application-oriented regulatory approaches can be developed.

This implementation plan describes the details of each research and development pathway including a broad set of research and development activities, a corresponding high-level schedule, and milestones over the next two decades. In many cases, these pathways are relatively mature and are based on more detailed life cycle plans, budgets, and schedules. This implementation plan also discusses the program management approach used by the Department of Energy to execute the Next Generation Nuclear Plant project, the largest single program relevant to this imperative.

Expanded use of nuclear energy, as described in this implementation plan, would provide enhanced energy security and retention of U.S. wealth by enabling deep reductions in oil and natural gas imports 
and substantially increasing the amount of liquid fuels produced from domestic carbon resources including bio-mass, coal, and low-grade crude oil. It can stretch the use of these resources by eliminating the need for them as heat sources for existing and future industrial activities. It is the only energy technology that can produce industrial quantities of energy without significant harmful emissions. With a modest technical investment, nuclear power can be adapted to the existing industrial infrastructure and significantly enhance our energy security within a few decades. 


\section{CONTENTS}

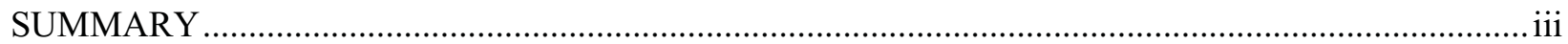

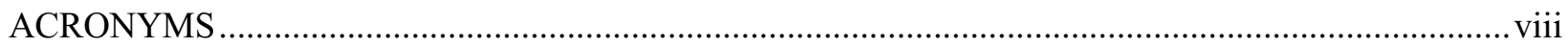

1. IMPERATIVE 3: ENABLE A TRANSITION AWAY FROM FOSSIL FUELS IN THE

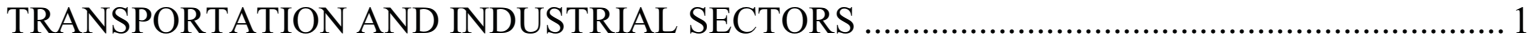

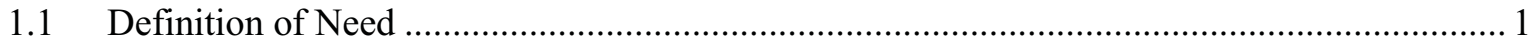

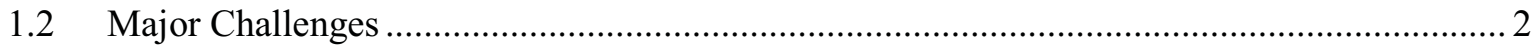

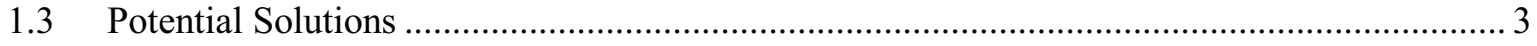

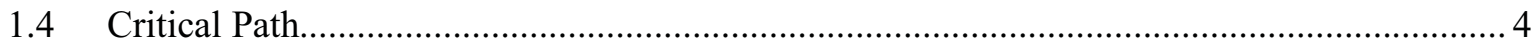

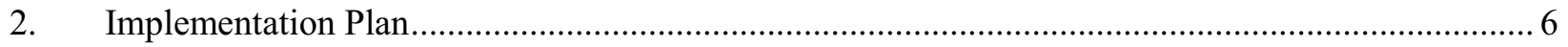

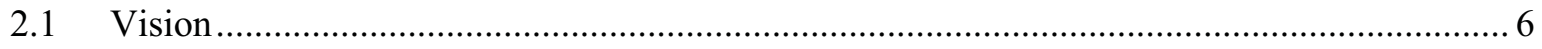

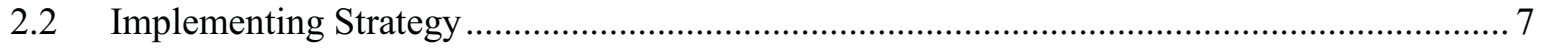

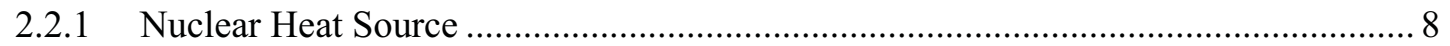

2.2.2 Development and Integration of the Reactor-Industrial End-User Interface ............ 10

2.2.3 Regulatory Approach, System Economics, and the Business Case ......................... 10

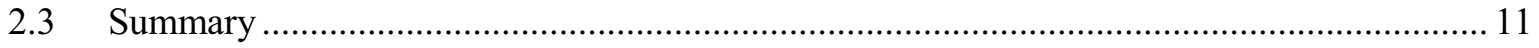

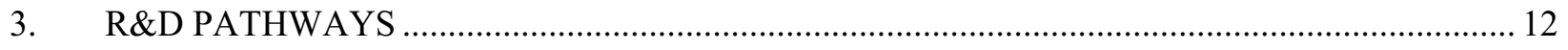

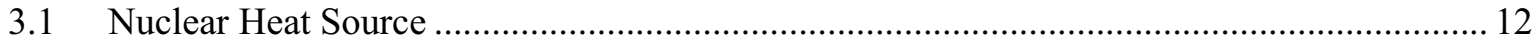

3.1.1 Next Generation Nuclear Plant (NGNP): A First of a Kind HTGR ........................... 12

3.1.2 Fuel Development and Qualification Program R\&D............................................ 14

3.1.3 Graphite Data and Qualification Program R\&D ..................................................... 17

3.1.4 High Temperature Materials Program R\&D ......................................................... 20

3.1.5 Design and Safety Methods Development and Validation Program R\&D ............... 22

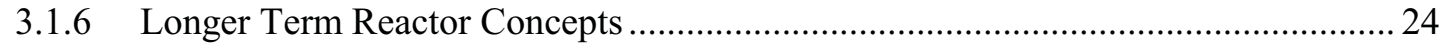

3.2 Development and Integration of the Reactor-Industrial End-User Interface ....................... 27

3.2.1 Heat Transport and System Integration............................................................. 28

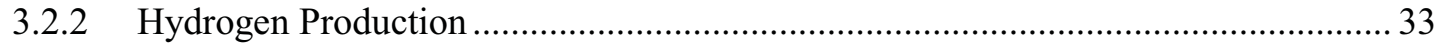

3.2.3 Feedstock Extraction and Processing for Hybrid Energy Applications ..................... 35

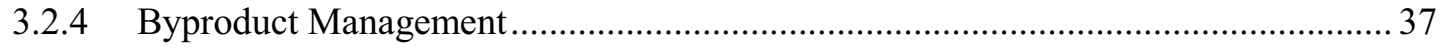

3.3 Regulatory Approach, System Economics, and the Business Case .................................... 39

3.3.1 Regulatory Approach and Required Innovation .................................................. 39

3.3.2 System Economics and the Business Case............................................................... 41

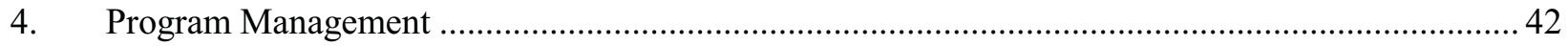




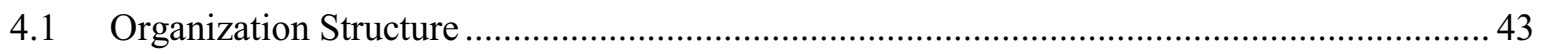

4.2 Roles, Responsibilities, Accountabilities, and Authorities ................................................ 43

4.2.1 Department of Energy - Office of Nuclear Energy ............................................... 43

4.2.2 Department of Energy - Idaho Operations Office ................................................ 43

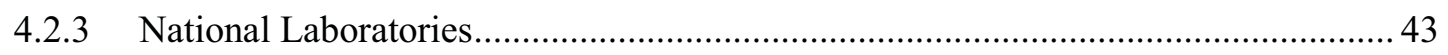

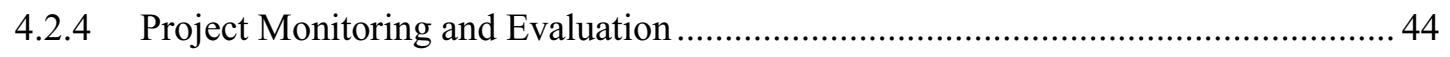

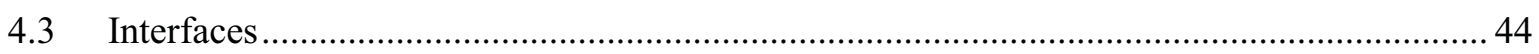

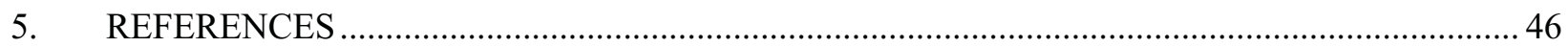

\section{FIGURES}

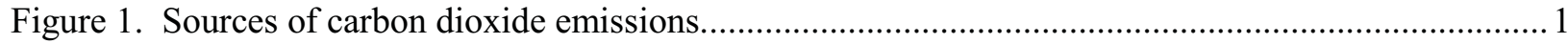

Figure 2. Key activities and demonstration points associated with Imperative 3................................. 5

Figure 3. Potential near-term U.S. industrial process heat uses versus temperature.................................. 7

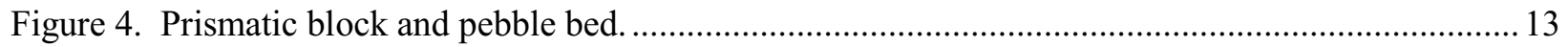

Figure 5. Previous and current high temperature gas reactor facilities................................................. 13

Figure 6. TRISO fuel and pebble bed and prismatic block fuel element designs.................................. 15

Figure 7. Fuel development and qualification program schedule ........................................................ 17

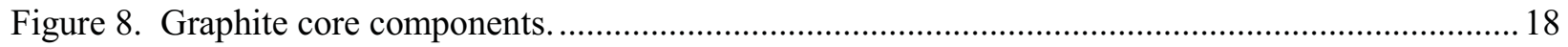

Figure 9. Graphite data and qualification program schedule ............................................................... 20

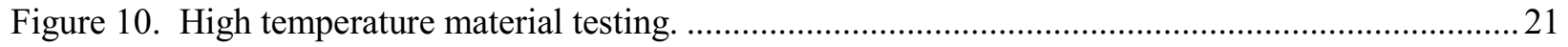

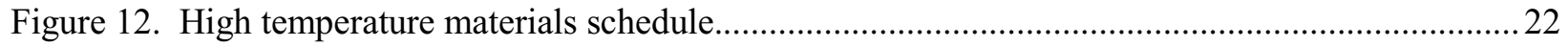

Figure 13. Experiments and computer simulations used in HTGR design and safety ...........................23

Figure 14. Design and safety methods development and validation schedule.......................................24

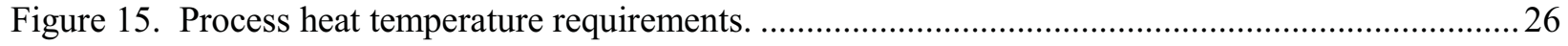

Figure 16. Examples of high temperature heat exchangers and circulators........................................... 30

Figure 17. Levels of Instrumentation and Control development and integration. ..................................31

Figure 18. Schedule of heat transport activities............................................................................. 32

Figure 19. HTE integrated lab-scale experiment (left) and three electrolytic modules (right).................33

Figure 20. Hydrogen production research schedule ........................................................................... 35

Figure 21. Feedstock processing R\&D pathway schedule

Figure 22. Total carbon management with carbon dioxide recycle using nuclear driven co-

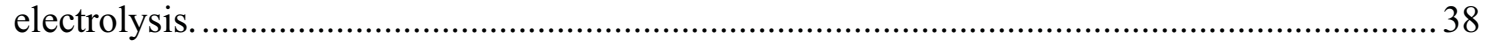

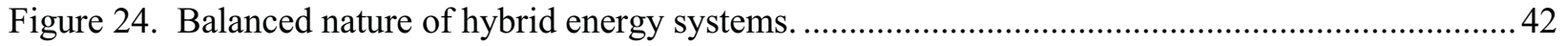




\section{ACRONYMS}

AHTR advanced high temperature reactor

ASME American Society of Mechanical Engineers

ASTM American Society for Testing and Materials

AGR Advanced Gas Reactor

CFD computational fluid dynamics

COL combined license

COLA combined operating license application

DOE Department of Energy

dpa displacements per atom

EPAct Energy Policy Act

FB fluidized bed

FSV Fort St. Vrain

Gen IV Generation IV

HES Hybrid Energy Systems

HTE high temperature electrolysis

HTGR High Temperature Gas Reactor

IHX intermediate heat exchanger

INL Idaho National Laboratory

I\&C Instrumentation and Control

ISI in-service inspection

LWR light water reactor

NEAC Nuclear Energy Advisory Committee

NGNP Next Generation Nuclear Plant

NRC Nuclear Regulatory Commission

PBMR Pebble Bed Modular Reactor

PIE post irradiation examination

PRA probabilistic risk assessment

R\&D research and development

RD\&D research development and demonstration

SCADA Supervisory Control and Data Acquisition

TRISO tri-isotropic

VHTR very high temperature reactor

ZLD zero liquid discharge 


\section{IMPERATIVE 3: ENABLE A TRANSITION AWAY FROM FOSSIL FUELS IN THE TRANSPORTATION AND INDUSTRIAL SECTORS}

\subsection{Definition of Need}

As shown in Figure 1, 70\% of the energy used in the transportation sector comes from imported oil supplies, creating energy dependence and vulnerability. ${ }^{1}$ Many other energy-intensive industries also rely on the burning of fossil fuels to supply the heat required for their activities. Furthermore, these industrial and transportation sectors are responsible for more than half of the greenhouse gas emissions in the U.S. Natural gas is a commonly used heat source, but natural gas is also used as an expensive feedstock for the chemical industry. Thus, burning it in power plants reduces the resources available to these industries and increases their costs. Reducing reliance on fossil fuels for thermal energy would also reduce the emission of potential harmful combustion products including $\mathrm{CO}_{2}$. In addressing these issues, it is important to examine the various ways nuclear energy can facilitate a transition to secure environmentally sustainable production and use of energy in both the manufacturing industry and transportation sectors.

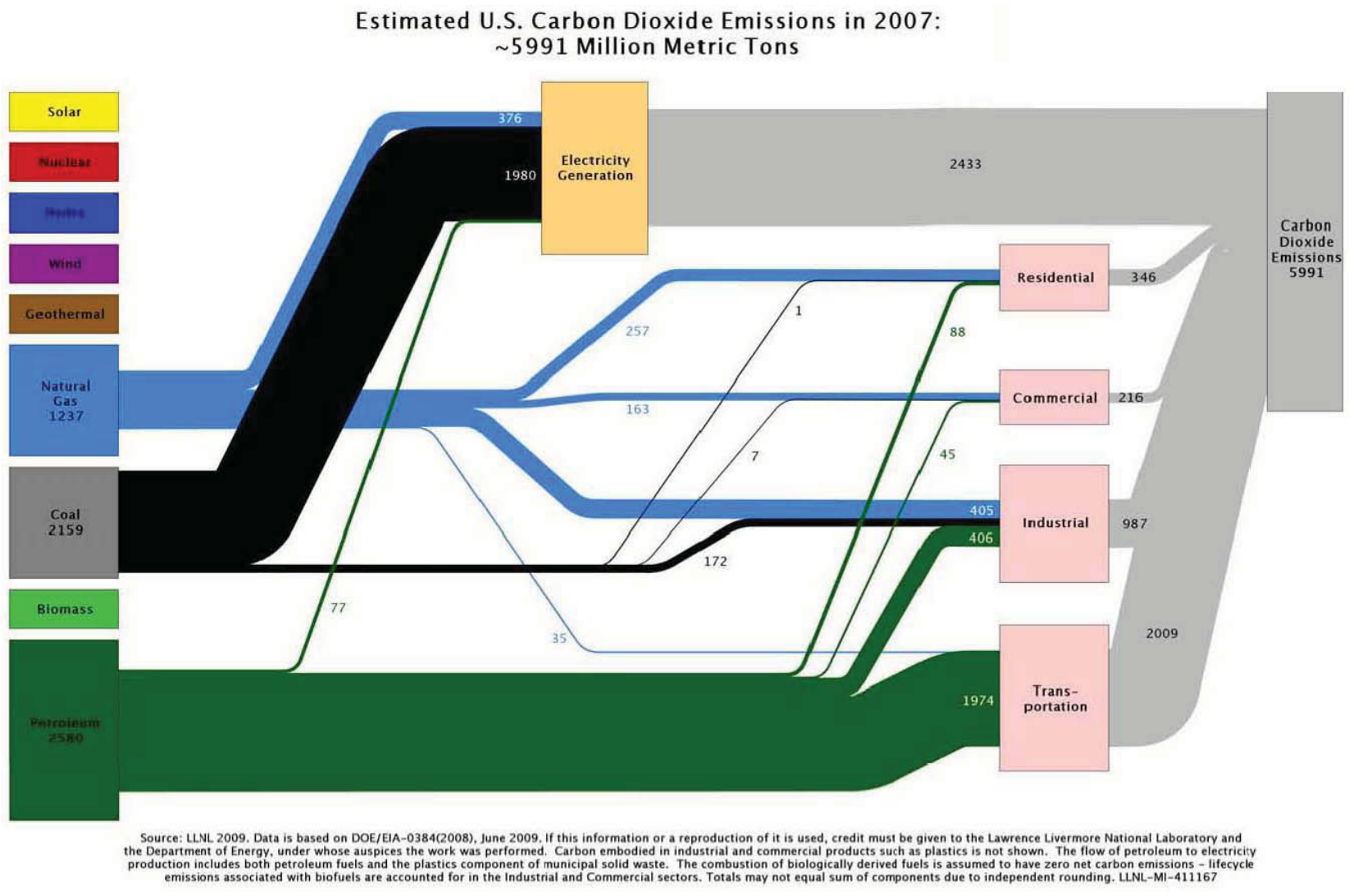

Figure 1. Sources of carbon dioxide emissions.

The full capacity of the 104 commercial nuclear power plants in operation today is currently used to generate base-load electricity. Nuclear power has the potential to be used to reduce the use of foreign sources of petroleum in the transportation and industrial sectors and the associated greenhouse gases produced, but new nuclear plant designs are needed to effectively meet these demands. This application of nuclear energy imposes different requirements on the design and operation of the reactor compared to those developed for electricity production only. Specifically, many industrial process heat applications require temperatures well above the 300 to $325^{\circ} \mathrm{C}$ outlet temperatures of light water reactors (LWR). 
Achieving higher output temperatures requires switching to alternative coolant technology such as gas, liquid metal, or liquid salt. With these coolants, it is possible to achieve outlet temperatures of over $500^{\circ} \mathrm{C}$ for liquid metal coolants and over $900^{\circ} \mathrm{C}$ for helium or liquid salt coolants.

Hydrogen is a major industrial feedstock currently produced through steam methane reforming, a process that typically uses fossil fuel and creates 8.9 kilograms of greenhouse gases (carbon dioxideequivalent) for every kilogram of hydrogen produced. ${ }^{2}$ Hydrogen is currently used primarily for (1) nitrogen fertilizer production, (2) petroleum refining, (3) the upgrading of heavy oil, oil sands, and coal into liquid fuels, (4) the production of chemical feedstocks, and (5) certain metallurgical processes, including steelmaking through direct reduction. The chemical process to remove sulfur from crude oil requires process heat input at $300^{\circ}$ to $400^{\circ} \mathrm{C}$. Massive amounts of heat are required in the $300^{\circ}$ to $800^{\circ} \mathrm{C}$ range for the processing of oil shale, oil sands, and petroleum. Direct Reduction Steelmaking requires heat at $800^{\circ}$ to $1050^{\circ} \mathrm{C}$. Many proposed processes to convert biomass to liquid fuels require hydrogen, such as the processes designed to maximize liquid fuel yields per ton of biomass. In the longer-term, hydrogen could be used directly as fuel in either fuel cells or hydrogen combustion engines.

Using nuclear energy to produce hydrogen would save the natural gas otherwise used, leaving it to be used as valuable feedstock in the chemical industries, and avoiding the emission of carbon dioxide.

Hydrogen could be produced using electricity from LWRs through either conventional or high temperature electrolysis, but more efficient and economical high temperature electrolytic and thermochemical processes using high-temperature reactors are on the horizon. Nuclear heat can also be in used in steam methane reforming, saving $20 \%$ of the methane required. Low temperature applications can be achieved using LWR technologies that are largely covered in Imperatives 1 and 2. Although Imperative 3 covers the full gamut of industrial applications for nuclear energy, the work presently done under Imperative 3 is focused on the research and development required to use advanced reactors to meet the needs for higher temperature process heat.

The objectives for Imperative 3 are to:

- Use and expand existing nuclear energy technologies in a cost-effective and reliable manner to enable a reduction of emissions of greenhouse gases from the transportation and industrial sectors.

- Develop and qualify the advanced technologies needed to enable reactors to provide process heat for a range of potential end users, including research on high burn up fuels and materials necessary to achieve very high outlet temperaturesDevelop interfacing heat transport, energy conversion, and hydrogen technologies that serve the end user in the industrial and transportation sectors.

- Establish the basis for licensing reactors that enable the process heat produced from nuclear energy to be delivered to industrial end users.

- Assist industry in the design, licensing, and construction of a demonstration nuclear heat source as part of the Next Generation Nuclear Plant (NGNP) program.

- Evaluate the economics and environmental characteristics of coupling a nuclear energy source to industrial applications to optimize deployment scenarios and establish credible business cases.

\subsection{Major Challenges}

Achieving reactor outlet temperatures from $500^{\circ} \mathrm{C}$ to over $900^{\circ} \mathrm{C}$ will require the use of new coolants and the development and qualification of specialized nuclear fuels, materials, and instrumentation, especially at the higher end of the temperature range. Using reactor coolants other than water will also require the development of a variety of plant components and systems such as electromagnetic pumps for 
liquid metal coolants, compact heat exchangers for gas coolants, and chemical purification systems for liquid salt coolants. Achieving outlet temperatures above $900^{\circ} \mathrm{C}$ will be extremely challenging technically. Material degradation by corrosion, loss of strength, and material compatibility issues pose fundamental barriers to achieving very high outlet temperatures based on existing materials. Research on advanced ceramics, composites and high strength metallic alloys will be needed.

Some requirements for process heat can be fulfilled through the use of electricity, either through heat pumps or electrical heating (resistance, induction, electric arc, microwave, and radio frequency), thereby allowing the use of current LWRs described under Imperatives 1 and 2. Thus, the efficient and economical generation of electrical power is a vital part of the transition away from imported oil, even if electricity is not the final product. Revolutionary thermodynamic cycles for the generation of electricity, such as supercritical carbon dioxide systems, are potentially important advances in the application of advanced reactors to industrial and transportation needs. Whether nuclear energy is used directly as process heat or through generation of electricity, higher reactor outlet temperatures inherently allow processes to be more efficient.

The challenges of using nuclear energy in markets other than electricity include the following:

- Industrial process heat applications require higher temperature reactors, efficient heat transport systems, interface systems for control and isolation, and development of a robust licensing case for co-locating the nuclear system with the industrial application.

- The transportation and industrial sectors are institutionally different from the electric power sector in terms of regulation, time horizons, market competition, and interfaces with the consumer.

- The use of high-temperature reactors, liquid metal-cooled reactors, and liquid salt reactors will produce used nuclear fuel forms different from LWRs. The storage and long-term management of these used fuels is described in Imperative 4.

The cost effectiveness and reliability of nuclear energy for industrial applications is yet to be determined.

\subsection{Potential Solutions}

The principal research, development, and demonstration (RD\&D) solutions are to develop:

- Reactors of the appropriate size and outlet temperature that cost-effectively supply process heat to industrial users.

- Interfacing heat transport systems that supply process heat with minimal losses to industrial users within several kilometers of the reactor. These heat transport systems must connect with the established technology now in use in these industrial processes, as well as with reactor control systems.

- Energy conversion technologies that apply nuclear energy for industrial and transportation fuels. Initially these energy conversion technologies will supply heat and hydrogen for the upgrading of fossil fuel resources (heavy crude oils, oil sands, oil shale, coal, etc.) production of ammonia for fertilizer, and converting biomass to the quality of current liquid fuels. In the longer-term, these technologies could accelerate the use of biomass and allow higher carbon utilization in the conversion of nonfood and waste biomass to liquids, thus producing two to three times more liquid fuel per ton of biomass. This would not only increase the amount of bio fuel that can be produced, but would also help conserve water and fertilizer. It will better conserve fossil fuels for uses where they are difficult to replace. In addition, direct synthesis of transportation fuels and 
other hydrocarbon products may represent another energy conversion technology for application of nuclear energy.

- Modeling and simulation capabilities. Modeling is needed at the following four levels:

- Systems integration and dynamics modeling, which characterizes the energy and material supply and demand of the electrical power and manufacturing industry (energy hybridization).

- Process steady-state modeling, which addresses the technical feasibility, environmental benefits, and economic basis (the business case) for the several nuclear-industry hybrid applications.

- Process and reactor-specific modeling and simulation of transient behavior necessary to understand, develop, and apply process controls for coupled nuclear and chemical systems.

- Fundamental heat transfer and reaction kinetics modeling that support technology design and operations, and also materials and processing systems qualification.

- Licensing strategies and business models that enable viable nuclear energy deployment scenarios in industrial settings. Locating a nuclear power plant in close proximity to an industrial plant along with coupling to the demand load of the industrial plant presents many challenges. The lengthy licensing review timelines typical of nuclear power plants will need to be shortened significantly, while maintaining a high-level of safety assurance, if nuclear power is to be a viable energy source for many industrial energy applications that are usually deployed on much shorter timelines.

\subsection{Critical Path}

The key milestones associated with Imperative 3 are shown in Figure 2. These milestones are designed to enable the use of the nuclear power in transportation and industrial sectors using a variety of reactors or the specialized optimized reactor systems noted above.

An important initial need, reflected in the 2012 milestone, is to coordinate the RD\&D for hybrid energy industrial parks in which wind and/or solar generation are integrated with nuclear energy and fossil feed stocks to provide a variety of low-emission energy products, including electricity, synthetic fuels, and hydrogen. 


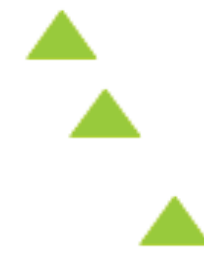

2010

2020

2030

2040

Figure 2. Key activities and demonstration points associated with Imperative 3. 


\section{Implementation Plan}

\subsection{Vision}

Expanding the use of nuclear energy beyond the power grid will contribute significantly to resolving three interlinked energy challenges facing industry and the U.S. government: rising and volatile prices for premium fossil fuels such as oil and natural gas; dependence on foreign sources for these fuels; and the risks of climate change caused by carbon emissions. Expanding nuclear energy into the industrial and transportation sectors could:

- Offset conventional fossil fuels by providing electricity for electric powered vehicles,

- Generate high temperature process heat and electricity for the production of valuable chemical feedstocks for the production of premium fuels and fertilizer products,

- Produce hydrogen for industrial processes and vehicles that utilize fuel cells,

- Provide clean water for human consumption by desalination and promote waste water treatment using low-grade nuclear heat, and

- Dramatically reduce greenhouse gas emissions.

These nuclear energy applications would also significantly contribute to the nation's energy security through more effective utilization of our country's natural resources while simultaneously providing economic stability and growth (predictable energy prices and high value jobs) in an environmentally sustainable manner (lower land and water use, decreased byproduct emissions).

However, the process heat needs for many petrochemical and other industrial processes require temperatures between 500 and $900^{\circ} \mathrm{C}$ as shown in Figure 3. This process heat demand will likely grow with the economy. Not included in the figure are higher temperature processes such as glass making, conventional steel making, and manufacturing of cement. These are extremely difficult applications and represent a small part of the overall process heat demand. 


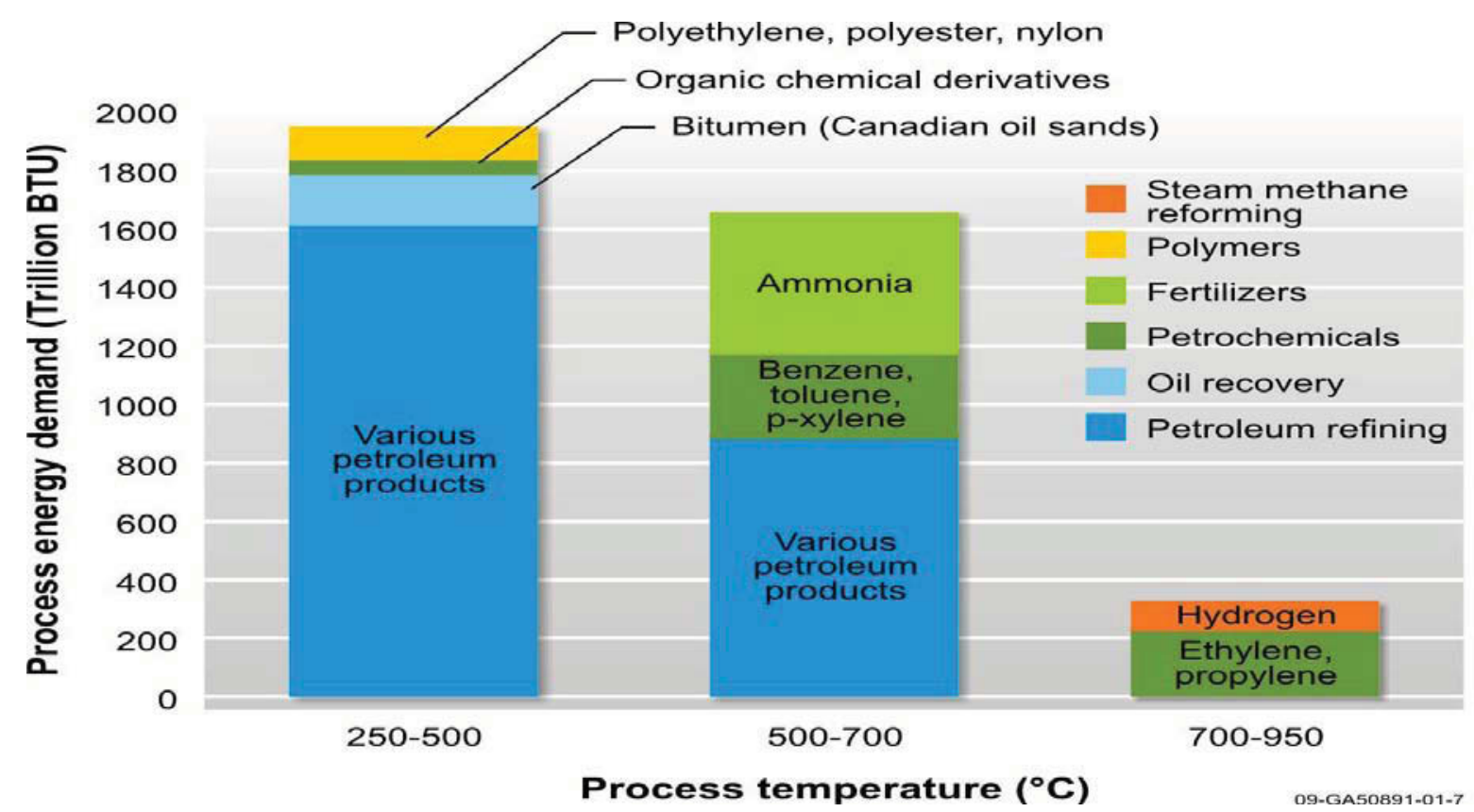

Figure 3. Potential near-term U.S. industrial process heat uses versus temperature. ${ }^{3}$

The temperature ranges of the process heat using industries can be met using a variety of reactor technologies. Up to $300^{\circ} \mathrm{C}$, LWRs are applicable, up to $550^{\circ} \mathrm{C}$ liquid metal reactors are applicable, and gas-cooled and salt-cooled reactors are applicable up to about $900^{\circ} \mathrm{C}$ with potential for exceeding $1000^{\circ} \mathrm{C}$. The Department of Energy supports each of these reactor types, but the near term emphasis for Imperative 3 is on gas-cooled reactors. The Next Generation Nuclear Plant is a high temperature gascooled reactor that is jointly being developed by the Department of Energy and industry. Because of its robust particle fuel and high heat capacity graphite core the High Temperature Gas Reactor (HTGR) is the nearest-term reactor concept that can provide process heat and electricity in a configuration that achieves a high degree of inherent passive safety, even in beyond design basis events, resulting in no significant fission product release from the core. Upsets in the industrial plant have minimal impact on the design and operation of the nuclear system because the combination of helium coolant and the solid graphite moderator make it a very loosely coupled nuclear system. These technical characteristics make it a good first candidate technology to integrate with industrial facilities and are very important in the licensing of an HTGR that would be collocated with an industrial installation. In the near term, most of the effort focuses on gas reactor technologies. In the longer term, other options (e.g., liquid salt cooled reactors) will be considered.

Electricity from LWRs can also be used for conventional low temperature electrolysis, other electrochemical processes, and electrical heating. The nuclear R\&D needs in this area are largely covered by the scope of Imperatives 1 and 2.

\subsection{Implementing Strategy}

DOE is working with industry to determine the needs of the end user in order to ensure that reactor technologies under development will meet those needs. This approach ensures that the Department's $\mathrm{R} \& \mathrm{D}$ activities will be done on a schedule to support the timely demonstration and deployment of new commercial technologies and applications. The strategy is based on a staged development in the near 
term with the high temperature gas reactor as embodied in the NGNP Project. In the longer term, concepts such as the VHTR and liquid salt-cooled reactors may be developed. ${ }^{\text {a }}$

The R\&D activities to execute this strategy have been organized into the following three major pathways:

- Nuclear heat source: gas-cooled reactor fuel, graphite, high temperature materials and improved computational methods to support, in the near term, the Next Generation Nuclear Plant Project, and in the longer term, to support other advanced reactor concepts for use as a nuclear heat source.

- Development and integration of the reactor-industrial end-user interface, including: heat transport and system integration, hydrogen production, feedstock extraction and processing for hybrid energy industrial park applications, and byproduct management.

- Regulatory approach, system economics, and the business case, including system economic and environmental assessments upon which more credible business cases can be developed.

\subsubsection{Nuclear Heat Source}

While LWRs have the potential for supplying process heat to certain lower temperature industrial processes (paper manufacturing, desalinization, agriculture, etc...), the nuclear energy technology effort for Imperative 3 is largely focused on an HTGR because the high outlet temperatures and high thermal energy conversion efficiency combined with inherent safety characteristics may enable a more cost effective and nearly risk-free integration with non-electricity applications. Detailed assessments of associated HTGR technologies indicate that they are sufficiently mature to merit consideration for industrial usage, but that the specific applications to process heat and co-generation need to be demonstrated. In the long term, other advanced reactor technologies such as liquid salt reactors may be used as a nuclear heat source when sufficient $R \& D$ has been conducted to make this a viable option.

The first-of-a-kind HTGR envisioned for the NGNP is an extension of past applications of gas-cooled reactor technologies, and will be driven by the near term commercial industry needs and current technology availability. The NGNP Project ${ }^{4}$ supports a transformative application of nuclear energy to address the President's goals for reducing greenhouse gas emissions and enhancing energy security. The NGNP Project was formally established by the Energy Policy Act of 2005 (EPAct 2005) (Public Law 109-58) to demonstrate the generation of electricity and/or hydrogen with a high temperature nuclear energy source. However, the objectives have evolved to consider process heat applications as discussions with potential end users have identified that as a broader and more important market. The Project is executed in collaboration with industry, the Idaho National Laboratory (INL) and other Department of Energy (DOE) Laboratories, U.S. universities, and international entities. The NRC is responsible for regulatory oversight.

Historically, our understanding of many aspects of HTGRs and the associated licensing basis has been empirical, based on technology and computational capabilities available in the 1970s and early 1980s. There is a need to apply state-of-the-art materials science examination and characterization techniques to provide a firmer technical basis for understanding the performance of the robust tri-isotropic (TRISO) fuel, the structural graphite and the high temperature materials under the demanding high temperature and high radiation environment anticipated in an HTGR like NGNP. In addition, more advanced computational methods and associated validation experiments are needed to address uncertainties in

\footnotetext{
${ }^{\mathrm{a}}$ In this Implementation Plan, HTGRs have outlet temperatures below $800^{\circ} \mathrm{C}$ and VHTRs above $800^{\circ} \mathrm{C}$.
} 
reactor design and safety analyses and to validate the analytical tools that are part of the licensing basis and ultimately to reduce unnecessary margin in plant design and operation.

The fuel development and qualification program will qualify TRISO-coated particle fuel for use in an HTGR like NGNP. TRISO-coated particles will be fabricated at industrial scale for use in formal qualification testing. The testing program consists of irradiations, accident safety testing, and post irradiation examinations that will characterize the behavior of TRISO-coated fuel under both normal and off-normal conditions. The program also contains out-of-pile experiments, special irradiations, and accident safety testing to characterize the release and transport of fission products from the kernel through the coatings, fuel matrix, graphite, and the primary system (i.e., source term). Formal validation testing is also planned to validate fuel performance and fission product transport models, required for core performance assessments and safety analysis.

In HTGRs, graphite is used as a moderator, reflector and a structural material. The objective of the graphite program is to measure the thermo-mechanical and thermo-physical properties for unirradiated and irradiated candidate grades of graphite for HTGRs that will form the qualification dataset for this material. Where practical, other grades of graphite may be tested and characterized to provide a baseline for comparison or to help understand material property changes for the candidate graphite grades. The program consists of statistical characterization of unirradiated graphite material properties to establish the lot-to-lot, billet-to-billet, and within billet variability of the material. Irradiations are planned at specified temperatures and doses within the design service condition envelope anticipated for an HTGR like NGNP. Extensive post irradiation characterization is planned to establish the change in relevant material properties as a function of temperature and neutron dose. From these datasets, constitutive relations will be established for use in a detailed predictive thermo-mechanical finite element performance and probabilistic failure models. These activities will establish a quantitative predictive understanding of graphite performance and a safe operating envelope for graphite. These data will also support development of relevant American Society for Testing and Materials (ASTM) standards and American Society of Mechanical Engineers (ASME) design rules. In the longer term, the program plans to evaluate processing route and raw material constituent influences on graphite behavior so that additional large qualification irradiation programs are not needed when new coke sources are used to make graphite for future HTGRs.

The goal of the high temperature materials program is to establish the relevant thermo-mechanical performance data to support the development of an Intermediate Heat Exchanger (IHX) and other high temperature components for a reactor coolant outlet temperature up to $900^{\circ} \mathrm{C}$. Creep, creep-fatigue, aging, and environmental degradation testing is needed using the candidate high temperature material selected for HTGRs. Thick and thin sections of base material, weldments and other joints (e.g. diffusion bonding) will be evaluated given the different design options under consideration for the IHX. Current candidate materials are Inconel 617 and Haynes 230. This material performance data at high temperatures will be needed to support relevant ASME code cases for the material. R\&D to establish requisite in-service inspection (ISI) techniques will be developed as key components are being designed. Prototype testing of key components is envisioned in a high temperature flow loop to characterize overall behavior under prototypic HTGR flow conditions to validate ISI techniques.

The present industries responsible for the manufacture of graphite and high temperature materials do not have the technical expertise and infrastructure necessary for qualifying these materials for use in nuclear reactors. Thus, the expertise and infrastructure in the National Laboratories is being called upon to support qualification of these materials for the NGNP.

The goal of the design and safety methods validation program is to develop experiments and data to validate models and analytical tools for the HTGR. As part of the effort, the program will resolve key safety, performance, and technical issues through confirmatory modeling and/or develop new tools when existing models and/or tools are judged inconclusive or inadequate. This work in the long-term will 
reduce uncertainties and improve the capability of understanding the behavior and operating margins of HTGRs.

The HTGR is the nearest term option that enables implementation of nuclear energy to meet the process heat and electricity needs of the industrial and transportation sector. In the longer term, two options offer potential benefits in terms of higher outlet temperature and high power densities: the VHTR, which is a helium cooled graphite moderated reactor with an outlet temperature in excess of $800^{\circ} \mathrm{C}$, and liquid fluoride salt cooled high temperature reactor (FHR) that uses a low pressure liquid fluoride salt instead of helium to cool the reactor. Both technologies will use much if not all of the R\&D needed for the HTGR but as discussed below in some cases will need extensions in fuels and materials qualification to enable their full potential.

\subsubsection{Development and Integration of the Reactor-Industrial End-User Interface}

An important part of the strategy is related to the integration of nuclear energy with non-electric enduser applications. System integration, diagnostics, and control are critical to the success of the overall effort. Development of validated system and process dynamic models and control algorithms that integrate the instrumentation from the nuclear plant with the diagnostics in the process application is an important focus area.

Establishing efficient and well-integrated means of transferring and transporting nuclear energy to the end-user application, especially at high temperatures, is a major challenge. This area will focus on developing advanced heat exchangers, evaluating process working fluids for the energy transfer for both short and long distance transfer applications, and designing and configuring systems that will meet the needs of a variety of industrial end user applications.

Coupling nuclear reactors to large chemical customers also poses scientific challenges. Analysis of the interaction between nuclear reactor kinetics and the kinetics of the industrial plant will require more sophisticated computer models. In addition, developing efficient and robust methods for producing hydrogen for some specific applications will require an understanding of the performance of solid electrolytic cells. The long-term application of massive amounts of heat and steam to fossil deposits will require an understanding of the behavior of geological formations in highly stressed circumstances.

Effective use of carbon feedstocks such as biomass, fossil carbon, and carbon dioxide in an integrated nuclear system is a critical feasibility issue for the development of hybrid energy systems. In addition, a variety of byproducts from such hybrid nuclear energy industrial park applications will impact the heat balance in the plant and will need to be managed. The ability to use a combination of electricity, process heat, and/or waste heat to recycle carbon dioxide and treat water produced by the system may be of importance from both environmental and economic perspectives. It is further necessary to understand how to integrate and operate hybrid energy systems and highly co-dependent plants.

\subsubsection{Regulatory Approach, System Economics, and the Business Case}

Finally, life cycle system analyses that consider various deployment options will need to be conducted to address overall system feasibility. Part of that assessment will address traditional economic metrics but will also need to include assessments against environmental metrics such as reductions in greenhouse gas emissions and uses of water, land, and carbon resources. Based on these assessments, more complete business models and regulatory approaches tailored to nuclear technology and non-electricity applications can be developed to determine potential private sector interest. 


\subsection{Summary}

Expanded use of nuclear energy would provide enhanced energy security and retention of wealth in the U.S. by enabling deep reductions in oil and natural gas imports and substantially increase the amount of liquid fuels produced from domestic carbon resources. Furthermore, nuclear energy allows the U.S. heavy manufacturing sector to reduce its greenhouse gas emissions in a cost effective manner and the transportation sector to reduce its carbon footprint while still using its current infrastructure. 


\section{R\&D PATHWAYS}

\subsection{Nuclear Heat Source}

\subsubsection{Next Generation Nuclear Plant (NGNP): A First of a Kind HTGR}

HTGRs are graphite-moderated nuclear reactors cooled by helium. Key characteristics of this reactor design are the use of helium as a coolant, graphite as the moderator of neutrons, and ceramic-coated particles as fuel. An HTGR can produce high temperatures, enabling applications such as process heat or hydrogen production for use in many industrial applications. Helium is chemically inert and neutronically transparent. The graphite core slows down the neutrons and provides high temperature strength and structural stability for the core and a substantial heat sink during transient conditions. The ceramic-coated particle fuel is extremely robust and retains the radioactive byproducts of the fission reaction under both normal and off-normal conditions.

The two major design concepts for HTGRs under consideration today are prismatic and pebble bed. In the prismatic configuration, hexagonal graphite blocks are stacked to fit in a cylindrical pressure vessel. Each block has cooling passages for helium and positions to place right circular graphite cylinders (about the size of a piece of chalk) that contain the coated fuel particles. Graphite reflectors surround the core to shape the neutron flux. The reactor is refueled with blocks containing new fuel every 12 to 18 months. In pebble bed designs, the coated fuel particles are formed into "pebbles" the size of a tennis ball. Graphite reflectors surround the pebbles to provide structural support of the core and reflect neutrons back into the core. Pebbles continuously circulate through the core. To obtain higher fuel efficiency and less stress on the fuel, the pebbles are recirculated a number of times during their three-year life before they are permanently discharged from the reactor.

Such fuels have been extensively studied around the world over the past four decades. This fuel is extremely resistant to physical degradation, provides robust protection for the nuclear material and assures outstanding retention of the radioactive byproducts produced during fission. Extensive testing in Germany in the 1970s and 1980s demonstrated that outstanding performance of coated fuel particles can be achieved under both normal operation and potential (but highly improbable) accident conditions. The passive safety of this concept derives from the outstanding performance of the fuel combined with the large graphite reflectors that act as a large heat sink. Furthermore, upsets in the industrial plant have minimal impact on the design and operation of the nuclear system because the combination of helium coolant and the solid graphite moderator make it a very loosely coupled nuclear system. These characteristics allow HTGRs to be located in close proximity to industrial complexes where they can provide heat for the high temperature chemical processes and hydrogen for chemical and petrochemical industries. Schematics of these two design options are shown in Figure 4.

The first of a kind HGTR envisioned for the NGNP is an extension of past applications of gas-cooled reactor technologies, and will be driven by the near term commercial industry needs and current technology availability. A number of prototype and demonstration high temperature gas reactors have been operated over the past 40 years. Two such reactors, one at Fort St. Vrain (FSV) and one at Peach Bottom, have been licensed by the Nuclear Regulatory Commission (NRC) and operated commercially in the U.S. Internationally, both pebble bed and prismatic reactors have been licensed and operated in the United Kingdom, Germany, Japan, and China. Photos of some of these facilities are shown in Figure 5. The focus of these systems has been electricity production. Modifications are needed to enable the production of process heat to meet the mission of the NGNP. 

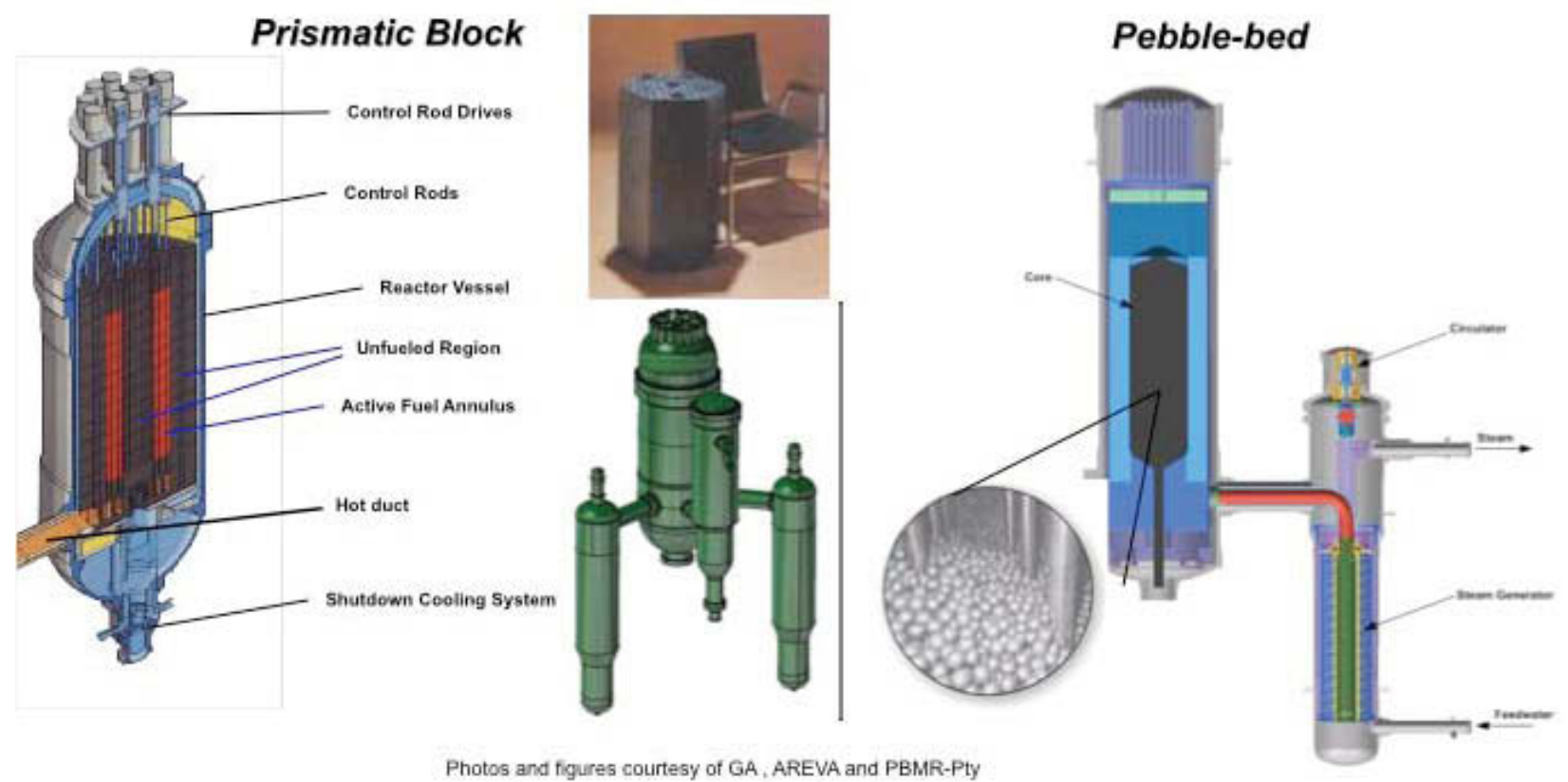

Photos and figures courtesy of GA, AREVA and PBMR-Pty

Figure 4. Prismatic block and pebble bed.

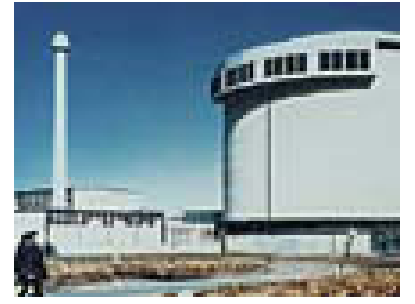

Dragon

(England)

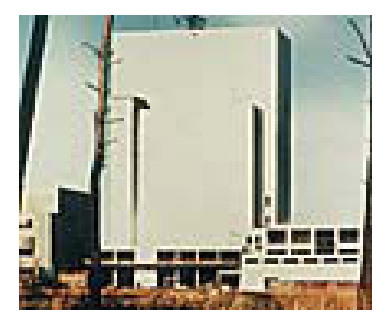

THTR

(Germany)

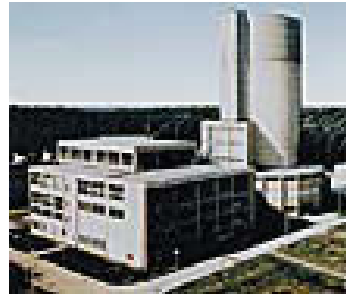

AVR

(Germany)

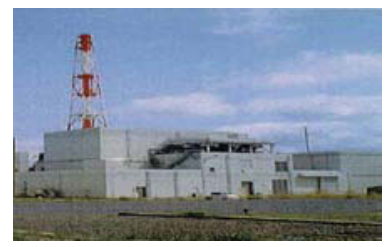

HTTR

(Japan)

Presently Operational

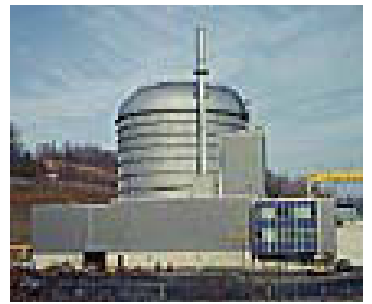

Peach Bottom

(U.S.)

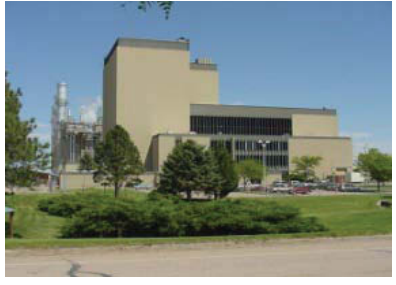

Fort St. Vrain

(U.S.)

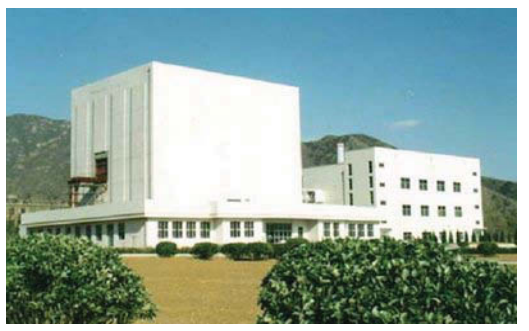

HTR-10

(China)

Presently Operational

Figure 5. Previous and current high temperature gas reactor facilities.

The NGNP Project ${ }^{4}$ supports a transformative application of nuclear energy to address the President's goals for reducing greenhouse gas emissions and enhancing energy security. The NGNP Project was formally established by the Energy Policy Act of 2005 (EPAct 2005) (Public Law 109-58) to demonstrate the generation of electricity and/or hydrogen with a high temperature nuclear energy source. However, 
the objectives have evolved to consider process heat applications as discussions with potential end users have identified that as a broader and more important market. The Project is executed in collaboration with industry, the Idaho National Laboratory (INL) and other Department of Energy (DOE) Laboratories, U.S. universities, and international entities. The NRC is responsible for regulatory oversight.

The NGNP Project includes design, licensing, construction, and R\&D conducted in two phases as defined in EPAct 2005. Phase 1 is pre-conceptual and conceptual design leading to the selection of a single technology for NGNP. Phase 2 is preliminary and final design leading to licensing and construction of a demonstration plant. Licensing scope supports the development of a licensing framework for high temperature gas reactors and includes the preparation and submission of a Combined Operating License Application (COLA) for the NGNP. Licensing and R\&D scope are included in both Phase 1 and Phase 2 of the project.

In September 2010, a programmatic review of the NGNP Project is planned to inform the Secretary of Energy on the readiness of the NGNP Project to proceed to Phase 2. The Secretarial decision on whether or not to proceed into Phase 2 is anticipated in January 2011. Phase 2 will begin with the selection of a single reactor design for demonstration as the NGNP. The conceptual design reports completed in Phase 1 will inform the competitive selection of a final design for the prototype reactor and plant. A Phase 2 public-private partnership agreement will be completed in 2011. Phase 2 will focus initially on finalizing the design of all safety systems in order to facilitate the preparation and submittal of a COLA to the NRC in 2013. Operation is anticipated in 2021.

Most of the challenges for the pebble bed and prismatic reactor types are held in common: licensing and regulatory issues associated with containment and emergency planning, business issues associated with breaking into new markets for nuclear energy in the transportation and industrial sectors, and infrastructure issues associated with first-of-a-kind technology demonstrations.

\subsubsection{Fuel Development and Qualification Program R\&D}

The HTGR concept is based on coated particle fuels, shown in the upper left of Figure 6. Such fuels have been extensively studied worldwide over the past four decades. The TRISO-coated particle fuel is formed by surrounding the uranium kernel (the active part of the particle) with layers of carbon and silicon carbide. The HTGR would contain billions of multilayered TRISO-coated particles. Either small cylinders called compacts or tennis-ball-sized spheres called pebbles (see Figure 6) are made from graphitic material with the tiny particles of fuel distributed throughout. Rigorous control is applied at every step during the fabrication process to produce high-quality, very low-defect, fuel. Defect levels are typically on the order of one defect per 100,000 particles.

The objective of the Advanced Gas Reactor (AGR) fuel development and qualification program is to qualify TRISO-coated particle fuel for use in the HTGR being designed and licensed by the NGNP Project. ${ }^{5}$ TRISO-coated particles must be fabricated at industrial scale, as opposed to in small batches in a laboratory, for use in qualification testing. The testing area consists of a variety of experiments and examinations that will allow an understanding of the behavior of TRISO-coated fuel under the radiation and temperature environment expected in an HTGR. The program also contains experiments to allow for an understanding of how the fission products, the elements produced when uranium fissions, stay inside or move outside of the coated fuel particles and through the graphite reactor core, (this is called the source term). Another important part of the program is the development of fuel performance and source term modeling and simulation computer tools and the associated physical testing to validate those tools for use in the design and safety analysis of the NGNP. 


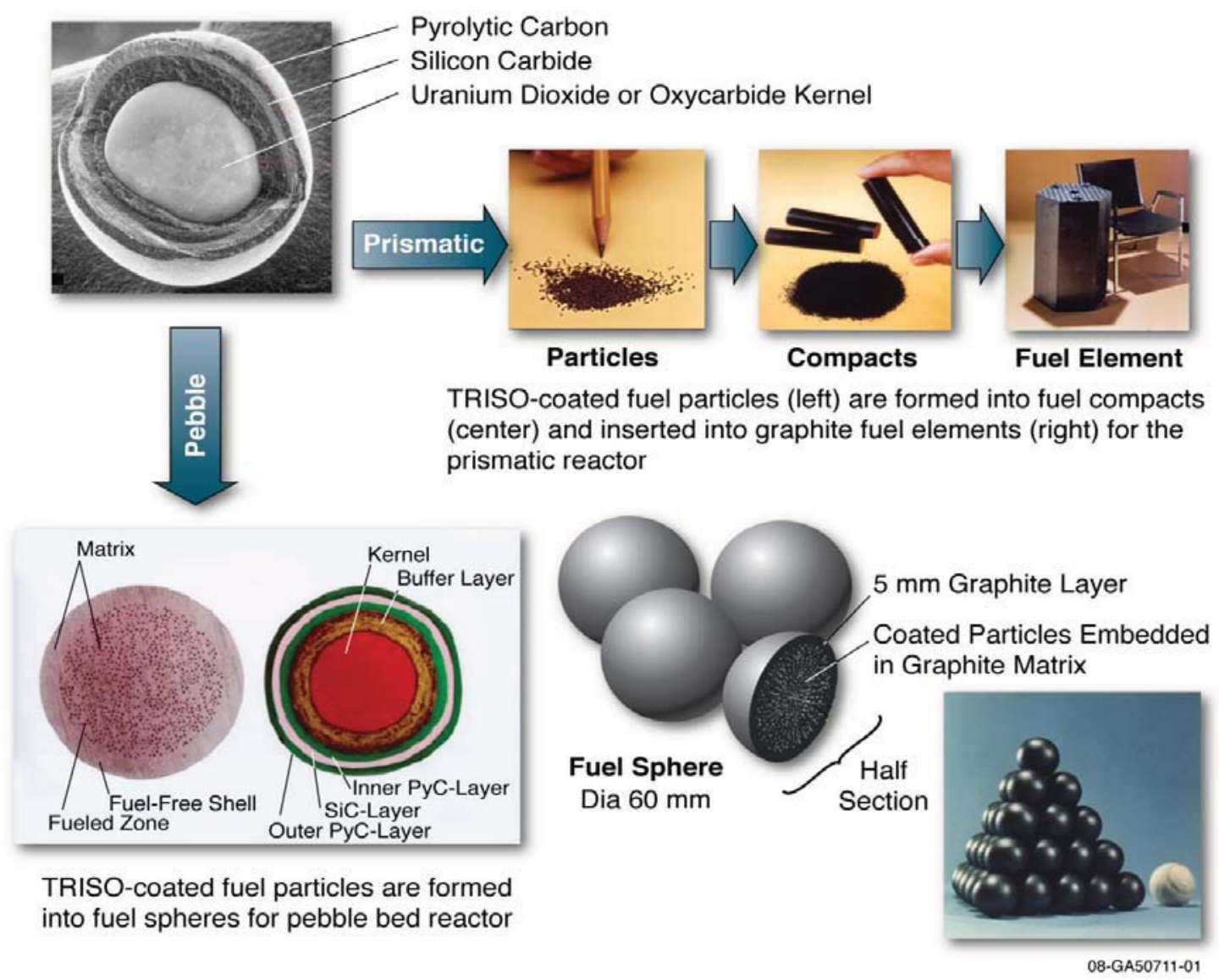

Figure 6. TRISO fuel and pebble bed and prismatic block fuel element designs.

The AGR fuel development and qualification Program involves five major program elements:

Fuel manufacture - This element addresses the work necessary to produce coated-particle fuel that meets fuel performance specifications and includes process development for kernels, coatings, and compacting; quality control methods development; scale-up analyses; and process documentation needed for technology transfer. This effort will produce fuel and material samples for characterization, irradiation, and accident testing as necessary to meet the overall goals. The plan also identifies work to develop automated fuel fabrication technology suitable for mass production of coated-particle fuel at an acceptable cost.

Fuel and materials irradiation - The fuel and materials irradiation activities will provide data on fuel performance under irradiation as necessary to support fuel process development, to qualify a fuel design and fabrication process for normal operation conditions, and to support development and validation of fuel performance and fission product transport models and codes. It will also provide irradiated fuel and materials as necessary for post irradiation examination (PIE) and safety testing.

Safety testing and PIE - This program element will provide the facilities and processes to measure the performance of TRISO fuel under normal operating and accident conditions. This work will support the fuel manufacture effort by providing feedback on the performance of kernels, coatings, and compacts. Data from PIE and accident testing will supplement the in-reactor measurements as necessary to demonstrate compliance with fuel performance requirements and support the development and validation of computer codes. 
Fuel performance modeling - Fuel performance modeling addresses the structural, thermal, and chemical processes that can lead to coated-particle failures. It does not address the release of fission products from the fuel particle, although it considers the effect of fission product chemical interactions with the coatings, which can lead to degradation of the coated-particle properties. Physical models and computer programs will be developed and validated as necessary to support fuel fabrication process development and plant design and licensing.

Fission product transport and source term - This element will address the transport to the exclusion area boundary of fission products produced within the coated particles to provide a technical basis for radiological source terms for HTGRs under normal and accident conditions. The fission product behavior task will provide primary source term data needed for licensing. The technical basis will be codified in design methods (computer models) validated by experimental data, as necessary to support plant design and licensing.

An underlying theme for the work scope presented in this plan is the need to develop a fundamental understanding of the relationship between the fuel fabrication process and fuel product properties and irradiation performance.

These tasks are organized into six major sets of activities on the schedule shown in Figure 7.

- Performance of laboratory scale fuel,

- Performance demonstration of industrial scale fuel,

- Moisture effects of fuel behavior given the presence of a steam generator in many HTGR process heat applications,

- Experiments to characterize the source term for HTGRs,

- Formal fuel qualification testing for fuel to be deployed in an HTGR, and

- Testing to provide data to validate fuel performance and fission product transport models.

In each of these cases, the activities include design and fabrication of test fuel and experiment test trains, irradiation testing of fuel, and safety testing and PIE.

High-level milestones for the fuel development and qualification program are:

- Complete performance demonstration of industrial scale fuel in 2015,

- Complete experimental source term characterization in 2016,

- Complete fuel qualification in 2017, and

- Complete model validation testing in 2018.

This high-level schedule is also shown in Figure 7. 


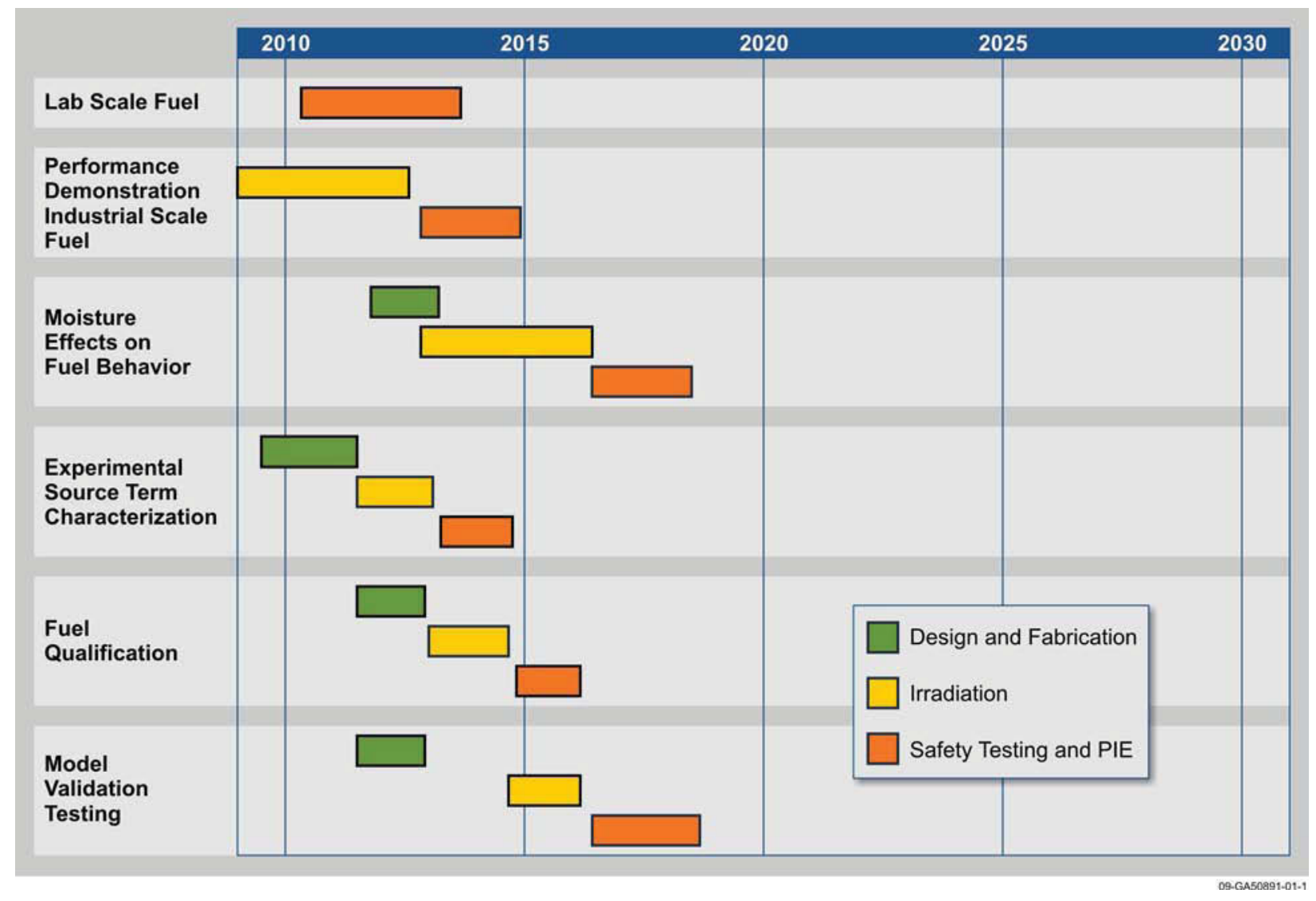

Figure 7. Fuel development and qualification program schedule.

\subsubsection{Graphite Data and Qualification Program R\&D}

In HTGRs, graphite physically contains the fuel and comprises the majority of the core volume. It also forms the inner and outer reflector (non-fueled) regions of the core. Graphite has been used effectively in the past as a structural and moderator material in both research and commercial high-temperature gascooled reactors, establishing graphite as a viable structural material for high temperature reactor cores (see Figure 8).

However, while the general characteristics necessary for fabricating available graphite are understood, the specific performance of currently available nuclear-grade graphite at the anticipated operating conditions is not known. Previous nuclear-grade graphite, such as H327 and H451 used in Fort St. Vrain, required an extensive development program that covered both fabrication processes and actual performance data to determine if they were suitable for reactor applications. Unfortunately, historical nuclear grades are no longer produced and the raw feedstock material (e.g., petroleum and pitch coke) used to fabricate the graphite is no longer available from the sources historically used. Thus, the new graphite grades and associated fabrication processes must be qualified. The approach to qualification outlined here is consistent with historical assessments of graphite qualification needs identified by gas reactor vendors, the NRC, and the ASME. The approach also factors in international experience, particularly in the UK where the current incomplete understanding of in-pile graphite behavior in British gas cooled reactors is causing the British utility to gather such data to respond to regulatory inquiries about the safety of those reactors in light of unexplained cracks found in graphite during reactor operation. 
As a result, the British are involved in a set of irradiations in Europe to better understand the grades of graphites used in their $\mathrm{CO}^{2}$ cooled high temperature reactors. South Africa and China also have active graphite programs. The Chinese are focusing on a Japanese grade of graphite, IG-110, for use in their high temperature pebble bed gas reactor. The South Africans are working with the European graphite supplier to optimize NBG-18, a graphite grade for use in the Pebble Bed Modular Reactor (PBMR) and are participating in graphite irradiations in Europe and the U.S. to understand the response of NBG-18 to neutron damage. Along with the U.S. and Europe, Japan, South Africa, and Britain are also involved in the international graphite collaborations under the Generation IV International Forum, and the IAEA to share data and knowledge with the ultimate goal of a better quantitative understanding of graphite behavior in high temperature reactors.

The new graphite grades will use new sources of unique petroleum and pitch coke in fabrication processes established previously. There is no irradiation experience with these new graphite types so there is currently no way to quantitatively predict how they will actually perform within a reactor environment. While the graphite will be structurally stable for some period of time, the lifetime (as a function of dose and temperature) is not known for the current grades of graphite. This is a critical safety issue in that the stability of the graphite must be understood to determine the structural safety of the internal core. Therefore, the new graphite grades need to be characterized to demonstrate that they exhibit acceptable nonirradiated and irradiated thermo-mechanical and thermo-physical performance. Fortunately, the technology for fabricating nuclear grade graphite has been established and a couple of graphite types are commercially available for testing and qualification. Current graphite grades suitable for use within both a pebble bed and prismatic HTGR design have been selected for further development.
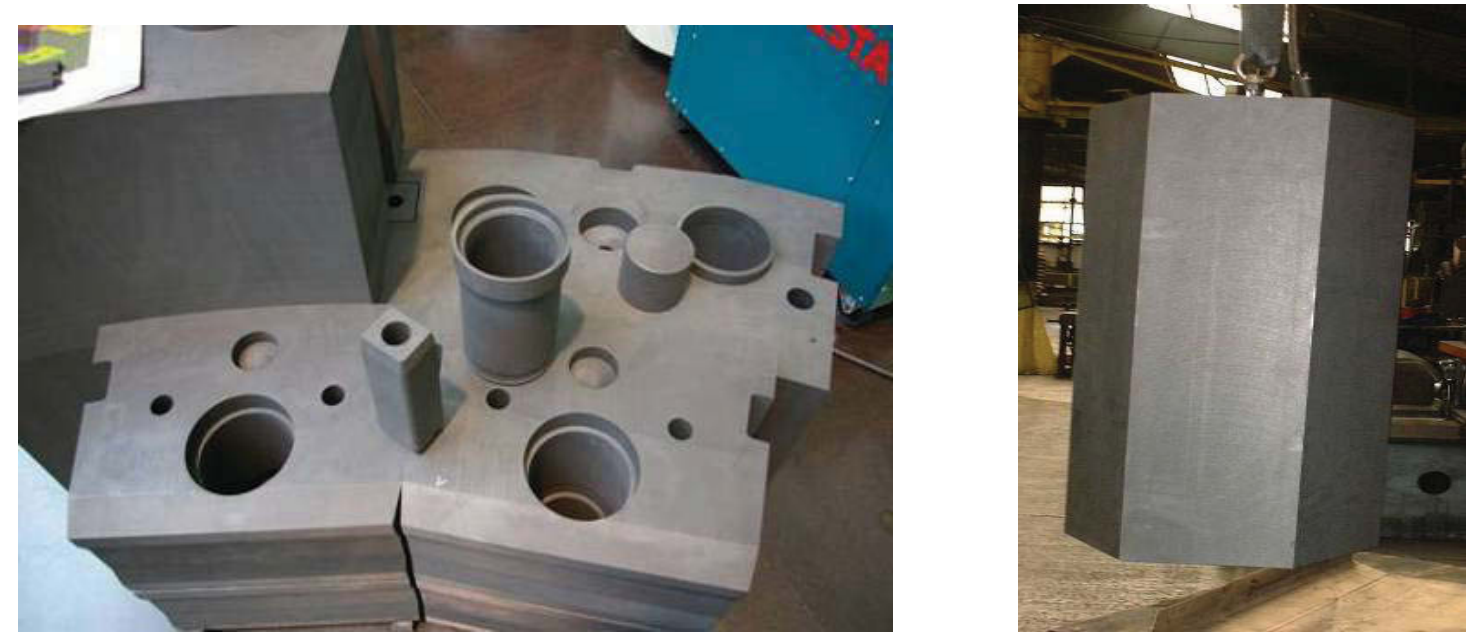

Figure 8. Graphite core components.

Thus, the objective of the graphite program is to develop the qualification dataset of thermo-mechanical and thermo-physical properties for unirradiated and irradiated candidate grades of graphite for HTGRs. ${ }^{6}$ Where practical, other grades of graphite may be tested/characterized to provide a baseline for comparison or to help understand material property changes for the graphite grades. These activities will demonstrate the performance of various graphite types, including irradiation dose levels, anticipated applied stress levels, and maximum core temperatures.

The program consists of statistical characterization of unirradiated graphite material properties to establish the lot-to-lot, billet-to-billet, and within billet variability of the material. This characterization will establish a quantitative baseline of material properties from which changes under irradiation can be understood. Irradiations are planned at specified temperatures and doses within the design service condition envelope anticipated for NGNP. An irradiation program has been proposed for a prismatic design that consists of eight irradiations that span the proposed temperature-dose envelope for a prismatic 
reactor. These irradiations will contain specimens of sufficient size, number, and type to support statistical assessments necessary to capture the inherent variability in graphite; to support traditional ASTM requirements for sample analysis; and to more completely characterize the physical, thermal, and mechanical properties of the irradiated graphite. For a pebble bed HTGR, additional irradiations would be needed to address the behavior of the graphite at higher dose, which could be accommodated in the current graphite irradiation program. Variability of key unirradiated material properties can be as low as $3 \%$ and as high as factor of 4 depending on graphite grade and the specific material property. Irradiation will further degrade some of the key properties (e.g., thermal conductivity, density).

The historic thermo-mechanical and thermo-physical irradiation performance database of graphite focused largely on moderate dose (5 to 7 displacements per atom (dpa)) and modest temperatures (400 to $850^{\circ} \mathrm{C}$ ), which is typical of the design service conditions of FSV and the older German pebble bed reactors. There is much less data at the higher temperatures and higher doses anticipated for the higher temperature designs. For a prismatic design with an outlet temperature of $900^{\circ} \mathrm{C}$, peak graphite temperatures could be as high as 1000 to $1250^{\circ} \mathrm{C}$ and the expected peak graphite doses in the reflectors could be 5 to 6 dpa with operation service lifetimes of about 6 to 10 years. The technology needs to satisfy requirements for the pebble bed are anticipated to be somewhat more substantial. While lower peak graphite temperatures of 1000 to $1100^{\circ} \mathrm{C}$ are expected, much higher doses are anticipated (25 dpa) because of the desire by the vendor to make the reflector a facility lifetime or near lifetime (changed once during the life) component. Thus, the new graphite grades need to be fabricated and characterized at these conditions to demonstrate they have acceptable performance within the more demanding environment.

Extensive post irradiation characterizations are planned to establish the change in relevant material properties as a function of temperature and neutron dose. A complete properties database for these new grades of graphite is required to describe the physical, mechanical, and oxidation properties of graphite. Of particular interest is the irradiation-induced creep of graphite, which is critical to determining the lifetime of the graphite under irradiation. From these datasets, constitutive relations will be established for use in a detailed predictive thermo-mechanical finite element model. Moreover, the data must be statistically sound and take account of in-billet, between billets, and lot-to-lot variations of properties. These data are needed to support the ongoing development of the risk-derived ASME graphite design code (a consensus code being prepared under the jurisdiction of the ASME by gas-cooled reactor stakeholders including the vendors). ASME codification of graphite will ease acceptance of this material for use by the NRC and reduce the risk to the reactor designer by establishing a safe operating envelope for graphite.

Beyond the near-term graphite qualification program, a more complete evaluation of the fabrication parameters and raw material constituents' influence on graphite behavior will be required for full commercialization of the nuclear grade graphite technology in the long-term. In addition, appropriate graphite recycling and disposal options must be considered to reduce the waste volume and the attendant costs of disposal. Recycle is considered as a long-term strategy and would only be pursued by vendors when large numbers of gas reactors are deployed. The magnitude of the R\&D program necessary to establish a standard nuclear-grade graphite, whether from a new coke source and/or from recycled material for use within any HTGR design, cannot be firmly estimated today given (a) the insufficient knowledge of the linkage between graphite fabrication, material properties, and in-reactor performance, (b) the more aggressive anticipated operating conditions for the high temperature process heat applications, and (c) issues related to long-term source availability and variability. It is anticipated that the work proposed to qualify graphite for the initial HTGR cores will provide the strong technical basis needed to establish a long-term graphite development and qualification program that meets these more ambitious commercialization goals.

High-level milestones for the graphite R\&D program are: 
- Complete baseline characterization of nuclear graphite grades in 2015,

- Complete characterization of low dose irradiation effects in 2017,

- Complete characterization of high dose irradiation effects in 2018, and

- Obtain ASME code certification in 2020.

A high-level graphite program schedule is shown in Figure 9.

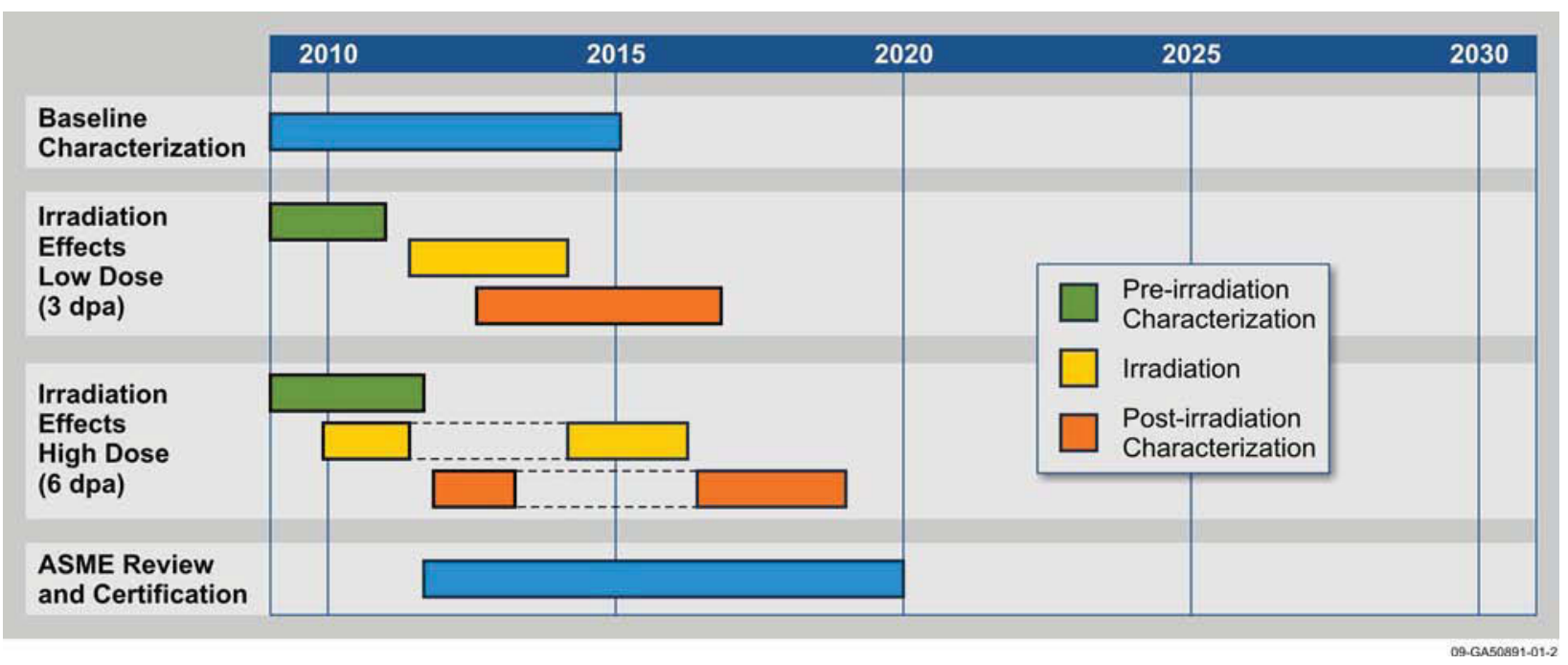

Figure 9. Graphite data and qualification program schedule.

\subsubsection{High Temperature Materials Program R\&D}

The high outlet temperature of an HTGR, above $750^{\circ} \mathrm{C}$, depending on the application need, requires the development of high performance metallic alloys to transfer heat from the reactor to the process application. Because these alloys will contain the high-pressure helium used to cool the reactor, stringent requirements are imposed to ensure that this piping and the equipment through which the helium flows, called the pressure boundary, will maintain its integrity. The ASME for assembles these requirements into code cases for use by designers to demonstrate structural adequacy to regulators. Today's high temperature alloys and associated ASME codes for reactor applications are approved only up to $760^{\circ} \mathrm{C}$. Thus, the goal of high temperature materials $R \& D$ pathway is to obtain the performance data required to support the development of these high temperature components and associated design codes over the broader range of envisioned outlet temperatures for HTGRs. ${ }^{7,8}$

A number of solid-solution-strengthened, nickel-based alloys have been considered for application in heat exchangers and core internals for an HTGR. The primary candidates are Inconel 617, Haynes 230, Incoloy $800 \mathrm{H}$, and Hastelloy XR. Based on the technical maturity, availability in required product forms, experience base, and mechanical properties at elevated temperatures, all of the NGNP preconceptional design studies have specified Alloy 617 as the material of choice for heat exchangers. A draft ASME code case for Alloy 617 was also developed in the past. Although action was suspended before ASME accepted the code case, this draft code case provides a significant head start for achieving material codification. Similarly, Alloy $800 \mathrm{H}$ is the material of choice for control rod sleeves, which is already listed in the nuclear section of the ASME code; although the maximum use temperature and time need to be increased. 
The objective of the high temperature materials R\&D pathway is to establish the relevant thermomechanical performance data to support the development of the IHX and other high-temperature components operating between 750 to $900^{\circ} \mathrm{C}$. Creep, creep-fatigue, aging, and environmental degradation testing is planned using the candidate high temperature nickel-based alloys such as Inconel 617 (see Figure 10). Constitutive models to describe the behavior of the alloy in tensile loading at elevated temperatures are also needed. Thick and thin sections of base material, weldments, and other joints such as diffusion bonding will be evaluated given the different design options under consideration for the IHX. Depending on the outlet temperature, additional high temperature data may be needed to support relevant ASME code cases for the material.

Additional scoping studies of potential degradation of the properties of IHX material candidates are required to characterize the high temperature interaction with the anticipated HTGR helium environment. Phenomeno-logical models for environmental degradation and greater understanding of the kinetics of degradation are needed to help bound the requirements for control of impurities in the primary and secondary helium during operation of the HTGR. Tests are specified to determine environmental effects on microstructure and properties.

The availability of large components, ease of fabrication, and nuclear service experience with the A508/533 steels strongly favor their use in the reactor pressure vessel for the NGNP, a near term application of an HTGR. This material selection reduces the amount of R\&D needed. The majority of additional information that is required is related to longterm aging behavior at HTGR vessel temperatures, which are higher than those commonly encountered in the existing database from LWR experience in the anticipated HTGR environment.

The $R \& D$ required to establish requisite ISI techniques will be developed as key components are being designed.

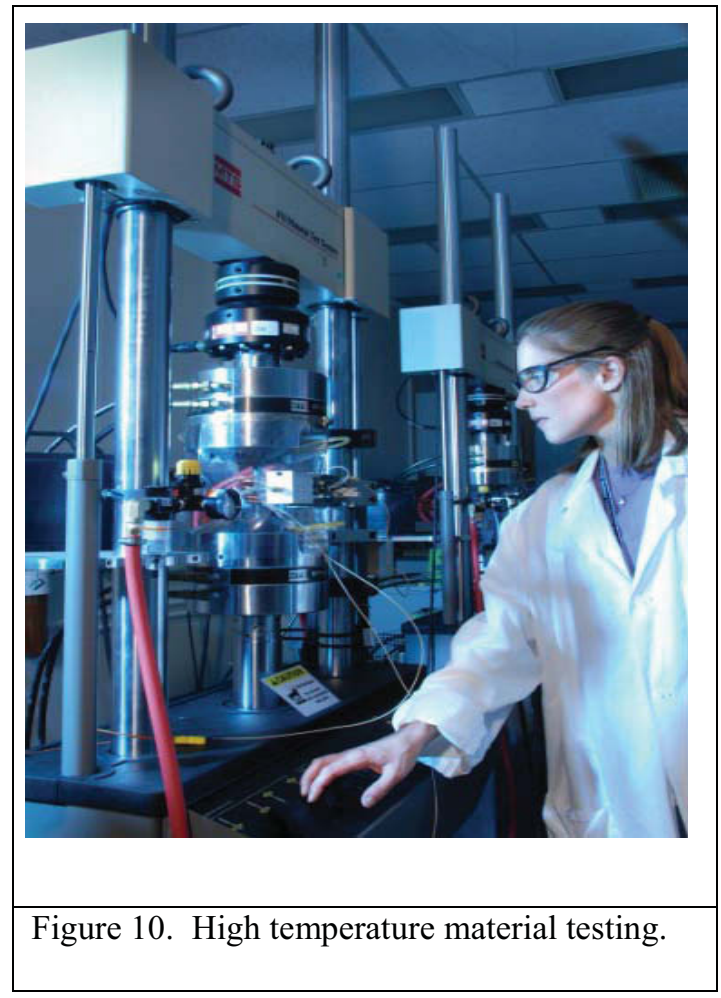
Prototype testing of key components is envisioned in a high temperature flow loop to characterize overall behavior under prototypic HTGR flow conditions and to validate ISI techniques.

As discussed in Section 3.1.6 to achieve higher temperature regimes, significant development is needed in the field of advanced composites for core structures. The need for R\&D on ceramic structures has been identified in studies commissioned by NGNP and reactor vendors have identified composite core structural materials as a key development need.

High-level milestones for high temperature R\&D programs are:

- Complete IHX testing in 2021,

- Complete characterization of alloy $800 \mathrm{H}$ in 2018 ,

- Complete RPV steel testing under HTGR conditions in 2018, and

- Complete longer-term creep testing for 60-year lifetime in the 2025 to 2030 time frame.

A high-level high temperature materials schedule is shown in Figure 11. 


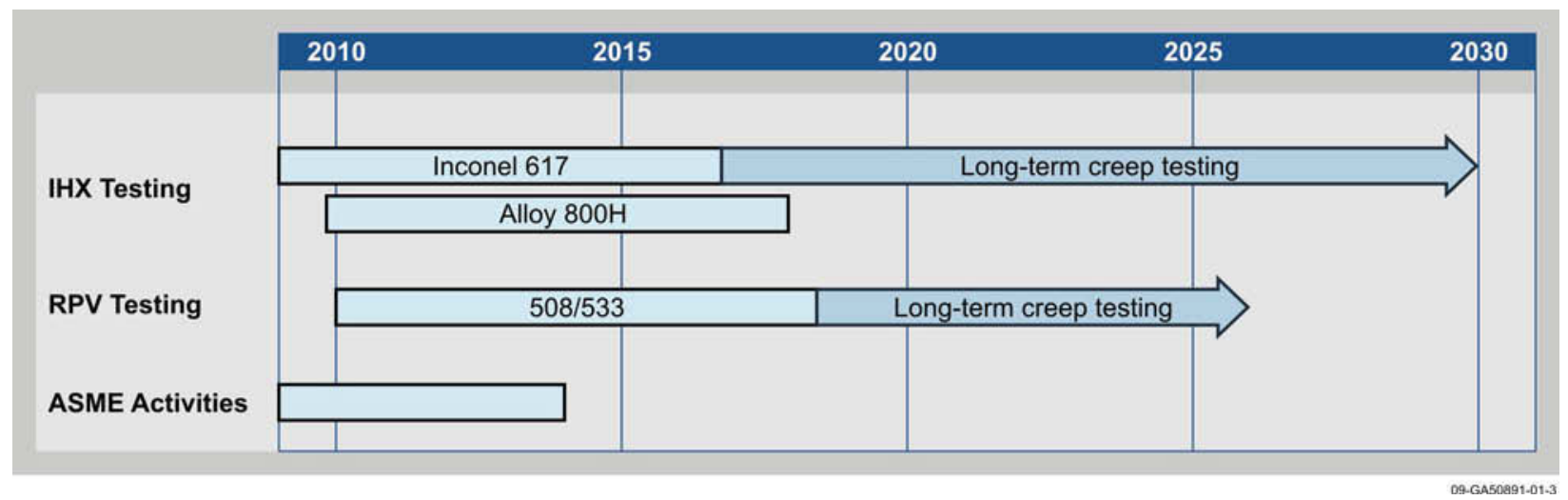

Figure 11. High temperature materials schedule.

\subsubsection{Design and Safety Methods Development and Validation Program R\&D}

An important activity in designing and licensing an HTGR is to confirm that the intended HTGR analysis tools can be used confidently to make technical decisions and ensure that all reactor systems are safe and meet the performance objectives of the design. The R\&D activities defined in the design methods development and validation program ${ }^{9}$ will ensure that the tools used to perform the required calculations and analyses can be trusted. The methods R\&D tasks are designed to ensure that the calculational envelope of the tools used to analyze HTGR reactor systems encompasses or is larger than the operational and transient envelope of the HTGR itself.

The methods R\&D pathway focuses on the development of tools to assess the neutronic and thermal fluid behavior of the plant. The fuel behavior and fission product transport models are discussed in the TRISO fuel development program.

The normal and off-normal scenarios and the associated physical phenomena that the reactor simulation programs can calculate with confidence define the calculational envelope of software used for HTGR designs. The software tools will only be used confidently once the results they produce have been shown to be in reasonable agreement with first-principle results, analytic solutions, and data that describe the highly ranked phenomena inherent in all operational conditions and important accident scenarios for the HTGR as expected by the NRC.

Considerable validation of existing tools is anticipated. The practices and procedures acceptable for both validating and developing the necessary software tools will be defined and implemented. New analysis methods and software must be developed if the current tools are shown to be deficient in their ability to simulate key safety and performance factors. Computational fluid dynamics (CFD) software, which has never been used in large measure to perform auditing, design, or licensing calculations for a nuclear plant, is anticipated to be widely used to analyze the HTGR behavior as has been used in used in aerospace and other industries . Although plant analysis software has been validated for specific cases, data must be generated for the wider range of HTGR phenomena that is anticipated for normal and offnormal operation.

The goal of the design and safety methods validation program is to develop experiments and data to validate models and analytical tools for the HTGR. As part of the effort, the program will resolve key safety, performance, and technical issues through confirmatory modeling and/or develop new tools when existing models and/or tools are judged inconclusive or inadequate. This work in the long-term will reduce uncertainties and improve the capability of understanding the behavior and operating margins of HTGRs. 
As a starting point, DOE researchers have participated with colleagues at the NRC using a wellestablished expert solicitation process to establish a ranking of important events that might occur during accidents in HTGRs. An optimal allocation of resources for safety-related R\&D activities was developed based on the importance of the specific accident-related event to the overall safety of HTGRs and the associated level of technical knowledge. Areas where the importance is high and the knowledge is low receive the greatest attention. Areas of focus include (a) assessing, benchmarking, and improving reactor physics and kinetic methods and data for prismatic and pebble bed HTGRs, (b) evaluating important phenomena that influence thermal-fluid behavior in HTGRs and establishing relevant scaled integral experiments for verification and validation, (c) evaluating air-ingress phenomena in HTGRs and participating in relevant validation experiments, (d) developing experiments to validate reactor cavity cooling system behavior, and (e) evaluating and establishing system level codes appropriate for HTGR safety analysis.
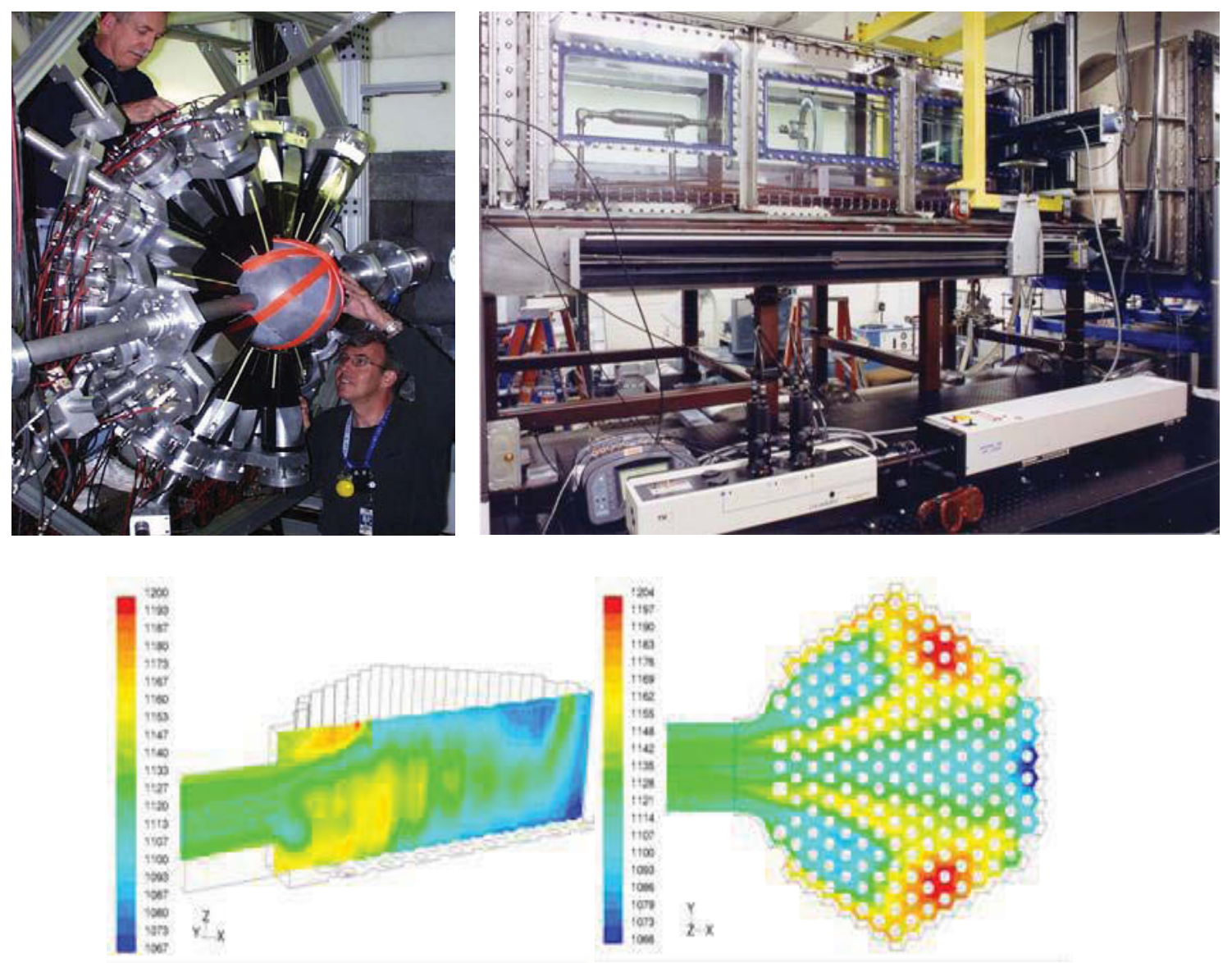

Figure 12. Experiments and computer simulations used in HTGR design and safety.

The methods R\&D pathway is interacting with the NRC to jointly develop a set of large-scale experiments to provide safety-related data that will be used independently by reactor designers and the NRC to validate modeling and simulation tools used to design a reactor or assess the safety of the design. This joint development effort avoids duplicative costly experiments by DOE and the regulator. The DOE and NRC have also initiated a joint collaboration with the Japanese gas reactor team to obtain unique operational data from their operating high temperature gas test reactor (the HTTR) to validate modeling and simulation tools that predict the behavior of the integrated reactor system. Assessments are currently underway by DOE, NRC, and laboratory personnel to technically evaluate other international capabilities that can be used to provide relevant safety data. 
The gas reactor vendors currently designing HTGRs such as the NGNP are still, in large measure, using their proprietary analysis tools to describe the operating and accident characteristics of their designs and intend to use them for licensing purposes. In addition, the NRC is establishing their set of analytic tools with which to perform confirmatory assessments of vendor calculations submitted as part of the NGNP Combined License (COL). Cross comparisons between this suite of tools (vendor tools, NRC code suite, and DOE software) and comparisons to the large scaled integral experiments are anticipated to improve design capabilities and confidence in all of the analytical tools and support licensing.

Beyond NGNP-specific methods work, advanced computational tools are under development by the modeling and simulation cross cut team to study HTGRs and very high temperature reactors (VHTR) at a greater level of fidelity and at smaller physical scales to understand the phenomena in these reactor systems that are not captured with existing tools. Technical areas under study include TRISO fuel; reactor physics and thermal hydraulics, and degradation of materials under harsh temperature and radiation environments.

A high-level methods schedule is shown in Figure 13. Methods R\&D will focus on applying, improving, and/or developing the tools necessary to predict the behavior of the candidate HTGR designs via separate effects testing, benchmarking, and developmental assessment. In the longer term, software tools will be validated using data from large scaled integral experiments.

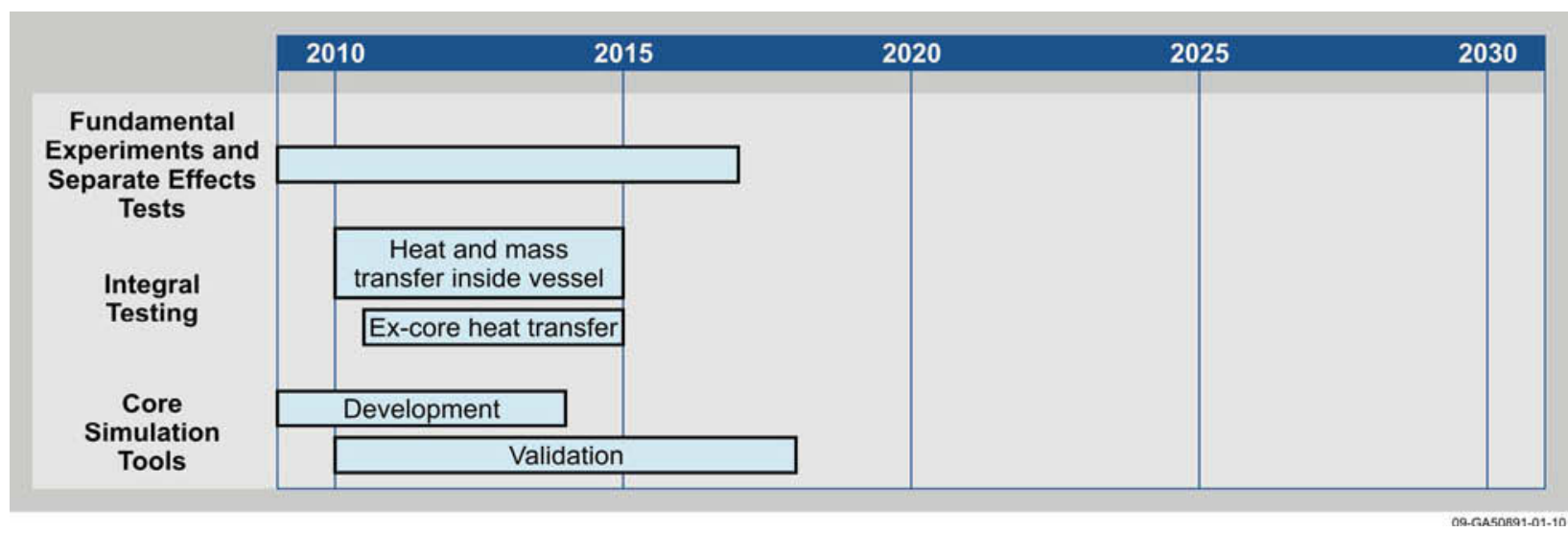

Figure 13. Design and safety methods development and validation schedule.

High-level milestones for Design and Safety Methods R\&D programs are:

- Complete development of core simulation tools, 2013

- Complete integral in-vessel safety testing, 2015

- Complete integral ex-core heat transfer experiments, 2015

- Complete fundamental separate effects tests, 2017

- Complete code validation and verification, 2018

\subsubsection{Longer Term Reactor Concepts}

The HTGR is the nearest term option that enables implementation of nuclear energy to meet the process heat and electricity needs of the industrial and transportation sector. In the longer term, two options offer potential benefits in terms of higher outlet temperature and high power densities: the VHTR, which is a helium cooled graphite moderated reactor with an outlet temperature in excess of $800^{\circ} \mathrm{C}$, and an FHR that uses a low pressure liquid fluoride salt instead of helium to cool the reactor. Both 
technologies will use much if not all of the R\&D needed for the HTGR but as discussed below in some cases will need extensions in fuel and materials to enable their full potential.

Very High Temperature Reactor (VHTR) - The VHTR is an extension of the high temperature gascooled reactor being developed as part of the NGNP. Its outlet temperature is envisioned to be in the range of 800 to $950^{\circ} \mathrm{C}$ to enable process heat applications at the highest application temperatures in Figure 14. The high outlet temperature is a particular challenge to the metallic components used in a gas reactor. The number of alloys available today to meet the mission is more limited at these temperatures and $\mathrm{R} \& \mathrm{D}$ is needed to develop improved intermediate heat exchanger/steam generator materials and steel alloys for the reactor pressure vessel to enable the high reactor outlet temperature operation.

The higher outlet temperature and a corresponding higher inlet temperature in some VHTR design options will shift the allowable thermal window for the reactor pressure vessel upwards in temperature to levels that would not allow the use of conventional LWR steel. While some engineering solutions such as active cooling of the vessel could alleviate this design constraint, the development of high strength creep resistant advanced ferritic steels would add flexibility and margin to the design options available for the VHTR design.

Nickel based alloys such as Inconel 617 and possibly advanced refractory alloys that retain their strength and creep resistance are potential avenues for exploration in use in high temperature duct and heat exchanger or steam generation applications.

With the higher outlet temperature in the VHTR, the average temperature in the reactor core also increases. Thus, for some of the reactor internals, as the average core temperature rises, the metallic components may be outside their acceptable operating range and need to be replaced by carbon-carbon and/or silicon carbide composites to enable operation (e.g. control rods) of the reactor.

While detailed designs of VHTRs have yet to be developed, the higher outlet temperatures may result in higher fuel and graphite temperatures that would require extensions of the qualification envelopes currently under development to support the HTGR. In addition, the impact of the higher temperature on reactor thermal behavior (hot streaking and mixing), hot spot analysis, safety performance, and resultant mechanistic source term would need further investigation.

Liquid Fluoride Salt Cooled High Temperature Reactor (FHR) - Liquid fluoride salts are an alternative, low-pressure coolant that maintains the passive safety of gas-cooled reactors at much larger power density and low primary system pressure. The improved accident heat rejection due to natural circulation liquid cooling essentially removes the gas-cooled reactor upper size limit imposed by the passive safety requirement to reject decay heat via conduction through the structural materials. While no liquid fluoride salt-cooled high temperature reactor has yet been demonstrated, much of their heat transfer system technology derives from the molten salt reactor technology demonstrated in two test reactors in the 1960s. Similarly, the technology envisioned by the FHR to reject heat under accident conditions is analogous to that of previously demonstrated pool-type liquid metal cooled fast reactors.

The structural materials challenges for a liquid fluoride salt cooled high temperature reactor are strongly related to those of helium cooled high temperature reactors in that both depend on high temperature nickel based alloys. The principal structural material differences between the two reactor concepts are the different chemical environments provided by liquid fluoride salt as compared to helium and in the lowering of the structural material strength requirements due to lower pressure, liquid cooling. The leading structural material approach for an FHR is to clad the structural alloy qualified by the NGNP project with a high nickel alloy that is well compatible with the fluoride salt thereby avoiding the need to develop a custom alloy.

Both the gas and liquid salt-cooled gas reactor variants employ coated particle fuel and thus would have similar fuel development paths. Liquid cooling, however, enables a larger (5-8 times) core power density. The performance of coated particle fuel under the higher flux conditions will require additional 
testing albeit at an accelerated rate. The less stringent pressure drop requirements for liquid phase cooling coupled with the necessity for more intimate coupling between the fuel and coolant at higher power density also alters the FHR fuel element design. This can be accomplished by either changing the coolant channel and fuel compact configuration in the case of prismatic fuel or decreasing the pebble diameter and locating the fuel particles near to the pebble surface in the case of a pebble bed core.

The accident response of low-pressure liquid salt-cooled reactors differs substantially from a gascooled system, thus the safety analysis and demonstrations necessary to provide adequate design confidence are distinct to FHRs. Single phase liquid cooling, however, provides strong similarity across experimental scales decreasing the effort required for safety performance demonstrations.

Lithium-7 is a useful primary salt isotope with both low parasitic neutron capture probability as well as sufficient moderating power to enable the reactor core to have a negative void coefficient. While a small domestic stockpile of Lithium-7 remains, the U.S. does not currently have industrial scale capability to separate lithium isotopes. Further, high chemical purity fluoride salts are not currently commercially available. Impurities within the coolant salt significantly increase its corrosive characteristics.

Consequently, fluoride salt purification technology demonstration will be an important element of an FHR technology development program.

The upper temperature of FHRs may be limited by the primary coolant boundary instead of the fuel. The ability to raise the reactor temperature and thereby its thermal efficiency without fuel redesign provides strong incentive to develop advanced composite ceramic materials both as salt-compatible thermal insulation as well as structural elements.

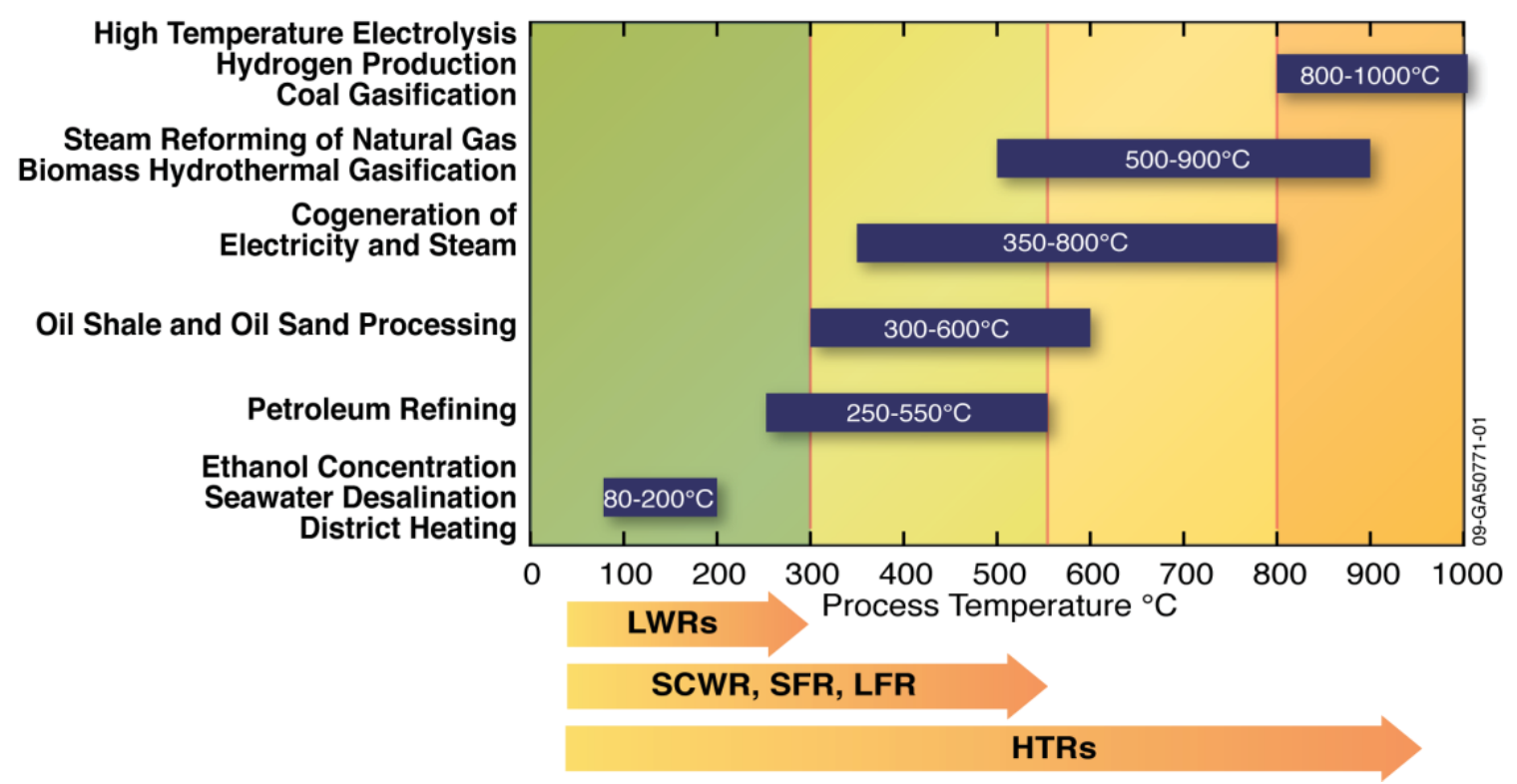

Figure 14. Process heat temperature requirements.

Other Options - Other classes of reactors could potentially be used to deliver process heat including $\mathrm{PbBi}$ reactors, sodium fast reactors, gas cooled fast reactors. In the near term, efforts will be focused on development of reactor system designs and technology development needs. In many cases it is anticipated much of the development can be built upon research underway as part of the NGNP Project or reactors being studied in Imperative 4. Once these designs mature, a system analysis activity will be used to screen those concepts for feasibility to deliver process heat for the temperatures above $850^{\circ} \mathrm{C}$. Key screening criteria include: process heat delivery temperature, ease of integration of the reactor with the 
end user process, technology development risk, licensing issues associated with co-location of the reactor and the end user facility, and economics. Although these other options could theoretically produce high temperature process heat, they lack many of the inherent safety characteristics found in gas reactors. This will make collocation with industrial processes extremely challenging.

\subsection{Development and Integration of the Reactor-Industrial End-User Interface}

Applying nuclear energy to industrial processes can significantly improve energy security in the U.S. by reducing greenhouse gas emissions and reliance on fossil fuel imports. Recent evaluations confirm the high potential to eliminate fossil fuel combustion by supplying direct or indirect heat for use $\mathrm{in}^{3}$ :

- Refining petroleum,

- Conversion of natural gas (methanol) to gasoline

- Producing unconventional fossil fuels (oil sands and heavy oil for extraction with steam and heated carbon dioxide; and oil shale for kerogen depolymerization and devolatilization),

- Hydrothermal gasification of biomass and coal to produce syngas (carbon monoxide and hydrogen) for synthetic fuels and chemicals,

- Producing industrial gases (in particular hydrogen), and

- Refining metals.

This list of applications requires hot gas or superheated steam ranging up to $900^{\circ} \mathrm{C}$, accounting for the temperature drop during heat exchange between the primary reactor gas of helium and candidate secondary working fluids, including helium, argon, nitrogen, or steam. The largest potential of industrial applications requires temperatures below $700^{\circ} \mathrm{C}$ as shown in Figure 1. The use of advanced nuclear reactors to provide process heat for a variety of industrial needs requires the development of technologies for efficiently transporting that heat from the reactor to the industrial plants.

Using nuclear-generated heat to produce liquid fuels and hydrogen can potentially play a key role in decreasing future U.S. petroleum imports, relieve the pressure on natural gas supplies, and convert lowgrade, dirty coal into high quality transportation and heating fuel that can be transported using the existing energy infrastructure. Hydrogen and process heat are needed today for upgrading and refining current crude oils and will be in even greater demand for refining unconventional fossil fuels in the near future. Further, in the future, hydrogen from nuclear energy will enable the efficient use of biomass for producing synthetic liquid transportation fuels. The use of nuclear hydrogen with biomass as the carbon source would allow the overall transportation sector to be nearly carbon-neutral. Hydrogen is also essential for producing anhydrous ammonia, nitrates, and urea for fertilizers. Today, $95 \%$ of the 9-million tons of hydrogen used annually in the U.S. is produced through the steam reforming of natural gas, with the accompanying release of 75 million tons of carbon dioxide. High temperature electrolysis (HTSE) is an efficient and modular method for producing hydrogen using nuclear energy. The combination of nuclear process heat and hydrogen can cleanly turn coal into products which produce more revenue per ton than current uses.

The range of temperatures needed for selected industrial heat applications is shown schematically in Figure 14. The distance between the reactor and the industrial plant may be as short as a few hundred meters in the case of co-located reactors and plants built on a green or brown field site, or as long as 10 $\mathrm{km}$ if the reactor is connected to an existing plant or new application that is geographically dispersed. Research is needed to determine the range of actual distances over which heat must be transported. 
Higher temperature heat, for example for metals refining, glass production, and cement production, can be obtained using the electrical power co-produced by the advanced reactor with resistive, inductive, electric arc, microwave, radio-frequency, and/or plasma gas heating. Alternatively, the hydrogen and oxygen produced by HTSE can be combusted with hydrogen or oxy-fired coal or oxy-fired gas burners. In each of these cases, clean, carbon-free energy can be imparted in the process if the energy is produced by a nuclear reactor.

Theoretically, all advanced reactors capable of producing high temperature process heat should be viable heat source options. However, because of its robust particle fuel and high heat capacity graphite core the High Temperature Gas Reactor (HTGR) is the nearest-term reactor concept that can provide process heat and electricity in a configuration that achieves a high degree of inherent passive safety, even in beyond design basis events, resulting in no significant fission product release from the core. Upsets in the industrial plant have minimal impact on the design and operation of the nuclear system because the combination of helium coolant and the solid graphite moderator make it a very loosely coupled nuclear system. These technical characteristics make it a good first candidate technology to integrate with industrial facilities and are very important in the licensing of an HTGR that would be collocated with an industrial installation.

\subsubsection{Heat Transport and System Integration ${ }^{b}$}

Economic substitution of reactors for fossil fuels in conventional processes requires integrated, efficient heat transport systems to exploit all of the reactor's heat. The major objectives in heat transport and system integration are:

- establish and model baseline heat transport and process configurations for applications with high potential for economical emissions reductions and efficient use of fossil fuels

- optimize the most promising integrated heat transport and process configurations; identify technology development needs to implement baseline configurations and for process improvements

- perform technology development studies that span the gap between fundamental research and technology demonstrations, including cross-cutting issues such as evaluation of thermal transients to and from the reactor and the process and tritium permeation through the heat transfer surfaces in the system

- create the component and pilot-scale testing infrastructure necessary for technology development, and for demonstration and validation of key components and integrated systems including monitoring and control strategies

- develop and validate modeling tools for components, systems and cross-cutting issues that impact coupling chemical and nuclear processes through component and pilot-scale testing.

Completion of the following tasks is needed for the heat transport and system integration program to meet these objectives.

Establish and Model Heat Transport and Process Configurations - Understanding industrial applications and available heat transport systems is necessary to establish a baseline to start from. Dynamic systems modeling can define nuclear-industry interfaces, incorporating heat, electricity and/or hydrogen production required to substitute nuclear heat for conventional energy sources. Further,

\footnotetext{
${ }^{b}$ The discussion presented here is based on an HTGR but is considered in broadest terms also relevant to longer term high temperature reactor concepts.
} 
dynamic systems modeling will characterize local and regional impacts from and on land resources, as well as air and water quality. By understanding all of the process requirements, efficient use of all of the reactor heat, including heat traditionally categorized as waste heat, can be achieved.

This activity therefore requires the development and use of detailed process models using commercial software that accurately represent heat integration, material balances, capital and operating costs. The models must be detailed enough to develop product costs based on: 1) available or close-to-market technologies; 2) current equipment and commodity costs, and; 3) economic factors such as internal rates of return, credit costs and potential emission taxes. By developing models and establishing an "art of the possible" baseline, selection of the most promising applications can focus subsequent optimization and prioritizations activities.

Optimize Heat Transport and Process Configurations, Identify Technology Development Needs The most promising integrated models should be optimized for impact to cost, emissions, resource conservation and energy independence. Economic evaluations should consider the needs of industry partners, as the business model needed to deploy a specific application may vary considerably. Evaluation of emissions, resource conservation and energy independence should consider factors such as spent fuel storage costs, infrastructure modifications, market penetration, job creation and time-dependent impact on national and international emission reduction goals.

Technology development needs should be based on deployment of the optimized flowsheets to maximize the benefit of the investment. Technology development can be categorized as close-to-market demonstrations needed to deploy baseline technologies, broad-based needs applicable to multiple applications, and more speculative technologies that offer the most improvement over the baseline. It is anticipated that substantial industry partnering will be needed for close-to-market demonstrations, as well as some of the development of broad-based technologies. Design of bench-, experimental-, and pilotscale experiments and facilities should be based on the technology development needs.

Technology Development Studies - This task explores the development of the primary components of the heat transport system. Heat transport is divided into three systems: heat transfer from the reactor core to a primary heat exchanger, secondary heat transport (via helium or steam as close-to-market applications and other fluids as potential process improvements), and deposition of the heat in the industrial processes. Technology development efforts are needed for each system. The heat exchanger between the primary reactor coolant of an HTGR (helium) at approximately $750^{\circ} \mathrm{C}$ and the secondary heat transfer medium is a critical part of the pressure boundary for the reactor. Development and demonstration of this component is key to deployment of first of a kind HTGR. The baseline technology for heat transfer from the primary circuit is steam production at approximately $535^{\circ} \mathrm{C}$, for which technology development needs are limited and primarily focus on performance of dissimilar metallic welds. Increasing steam temperatures or hot gases used as a secondary fluid increase the complexity of new materials, fabrication methods and components with increasing benefit for process applications in terms of thermal efficiency. Demonstration of heat exchangers benefits heat transport in all three systems.

High temperature material compatibility is a concern for all combinations of heat exchanger materials, bonding and fabrication technologies, and coolant chemistries. Developmental studies to determine optional configurations need to be performed that will explore configurations of heat exchangers (see Figure 15) and the associated high temperature material options ranging from conventional (e.g., metallic shell and tube) to more advanced and innovative technologies (compact heat exchanger, ceramic heat exchanger) in conjunction with candidate transport mediums. Issues related to materials compatibility, heat transfer effectiveness, and structural robustness will be studied for the relevant application. Direct and indirect gas contact heaters need to be investigated for heat deposition. To facilitate broader application and long-distance transport of energy, longer-term research is needed to extend the use of 
molten salts from their current applications to temperatures above $600^{\circ} \mathrm{C}$. The use of electrical power and combustion topping cycles also needs to be evaluated.
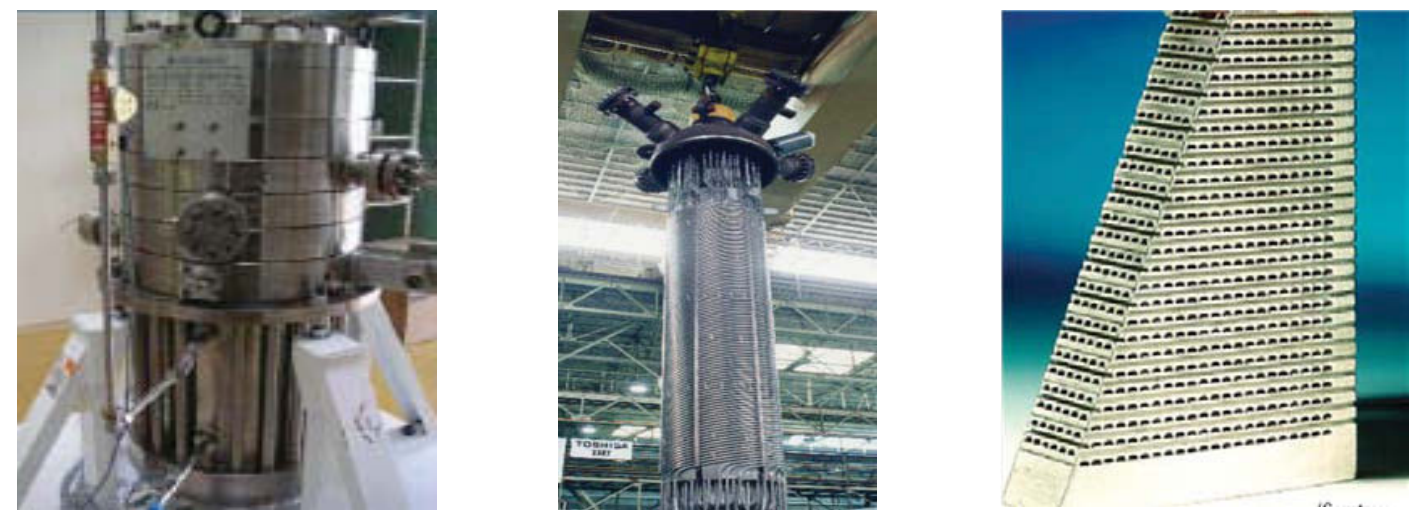

Figure 15. Examples of high temperature heat exchangers and circulators.

Tritium permeation, thermal transients and water management are cross-cutting issues that will affect heat transport systems and process applications and require integration with planned R\&D. Permeation of tritium generated in the reactor primary circuit increases with an increasing temperature. While tritium is not a significant contributor to the reactor source term, its mobility creates the potential to contaminate industrial products, emissions, and discharges. The modeling, development, and demonstration of tritium removal systems are required. Whereas process heating is typically not a steady-state operation, transients in heat transfer and thermal inertia will need to be investigated and understood. Water management is vital to successful management of the reactor and most potential industrial applications.

Based on the results of these studies, technology development and test plans will be developed. Integrated testing will be conducted in accordance with the plans to investigate component response, component reliability, and system behavior in the relevant environment. Small-scale integral testing will validate the technology while concurrently supporting the development and demonstration of instruments and monitors for process control.

Create Component and Pilot-scale Testing Infrastructure - Bench-, experimental-, and pilot-scale tests are needed to evaluate single-effects and integrated system performance of new process-specific heat exchangers, components and technologies. Such testing will validate simulation predictions and demonstrate component performance. Enabling technologies such as demonstration of fabrication and inservice inspection techniques can typically be demonstrated at smaller scales. Short-term and single effects tests with faster turnarounds and multiple iterations are also performed more economically at small scales.

Long-term testing will provide the reliability data needed to ensure the system will meet the high availability anticipated by the end users can also be performed at small scales. Integrated and larger component tests will be performed at larger pilot scales and can provide system performance data and demonstration of monitoring and control systems. Long-term and integral tests are typically more complex and require more extensive instrumentation and scaling studies. Regardless of the scale or length of test, facilities will be designed for flexibility to ensure their continued value for ongoing use after the first application is tested. 
Monitoring and control development includes developing sensors/actuators, managing data, and demonstrating control systems. A hierarchical modeling and simulation framework is envisioned. Each layer of the hierarchy will be informed by its parent layers and receive appropriate process data from the monitoring system. Flexibility for accommodating sensors and actuators with different levels of accuracy, precision, intelligence, and operability response would be beneficial for the integration of nuclear energy into non-electric applications. Integrated systems of smart sensors must self-assess plant conditions, regulate process variables, and relay information and knowledge pertaining to multiple unit operations. A flexible actuator capability is needed to regulate actions exerted by systems of distributed actuators. While secure data acquisition systems based on wired and field bus technologies are anticipated, wireless options may also be considered based on their intrinsic flexibility. To best meet particular information requirements and constraints, promising information architectures and infrastructures need to be investigated for efficient and secure operation.

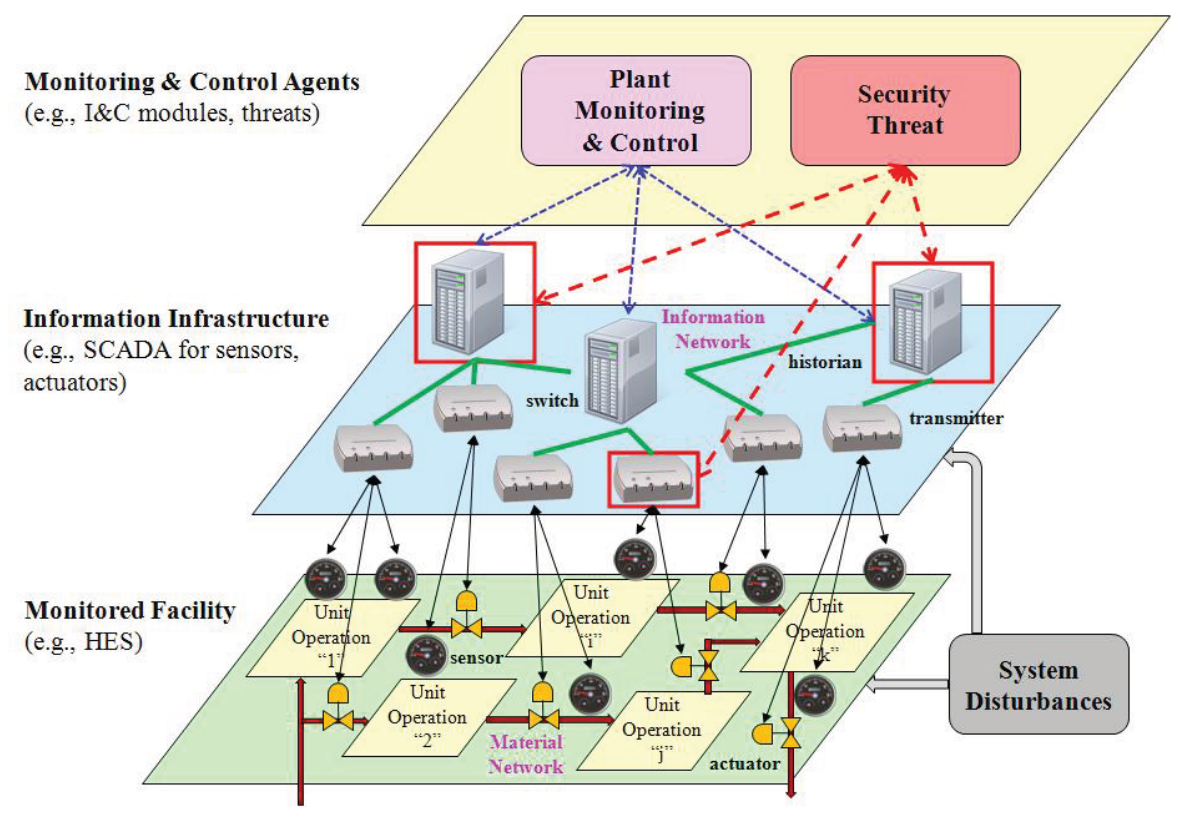

Figure 16. Levels of Instrumentation and Control development and integration.

Because the reactor concepts are expected to increase reactor outlet temperatures as they mature, test facilities will be designed to accommodate steady state and operational transients for the higher outlet temperatures. It is expected that test priorities will generally consider lower temperature technologies first and schedule longer-term technology development tests around the lower temperature, close-tomarket tests.

Heat transport and system integration milestones for creating testing infrastructure include:

- Complete design and fabrication of experimental scale facilities by 2012.

- Complete pilot-scale demonstration, design, and construction in 2013.

- Complete demonstration of pilot-scale plant heat transfer to first industrial process in 2016 (planning basis is approximately $2 \mathrm{MWt}$ transferred to High Temperature Steam Electrolysis model).

Develop Modeling Tools and Validate through Testing and Demonstration - Single-effects and pilot-scale component testing is needed to demonstrate new process-specific heat exchangers and other components needed to transport heat to the end user application. Computer models for specific processes, 
and heat transport components and systems ranging from the atomistic level to macro-scale have been, and will continue to be, developed. Validation of those models through testing and demonstrations is needed to deploy integrated heat transport systems at commercial scale.

Long-term testing will provide the reliability data needed to ensure the system will meet the high availability required by the end users, and in some cases required by regulatory and standards organizations. Testing is often iterative in that the results identify additional needs or opportunities. Once the test systems and experimental facilities are built and operated for the first application, the need for additional industrial applications will require their continued operation.

Heat transport and system integration milestones include:

- Complete heat-integration system conceptual design based on technology development modeling simulations in 2014.

- Complete pilot-scale demonstration, design, and construction in 2016.

- Complete demonstration of pilot plant heat transfer to support full-scale engineering design in 2018.

A schedule of the heat transport and system integration activities is shown in Figure 17.

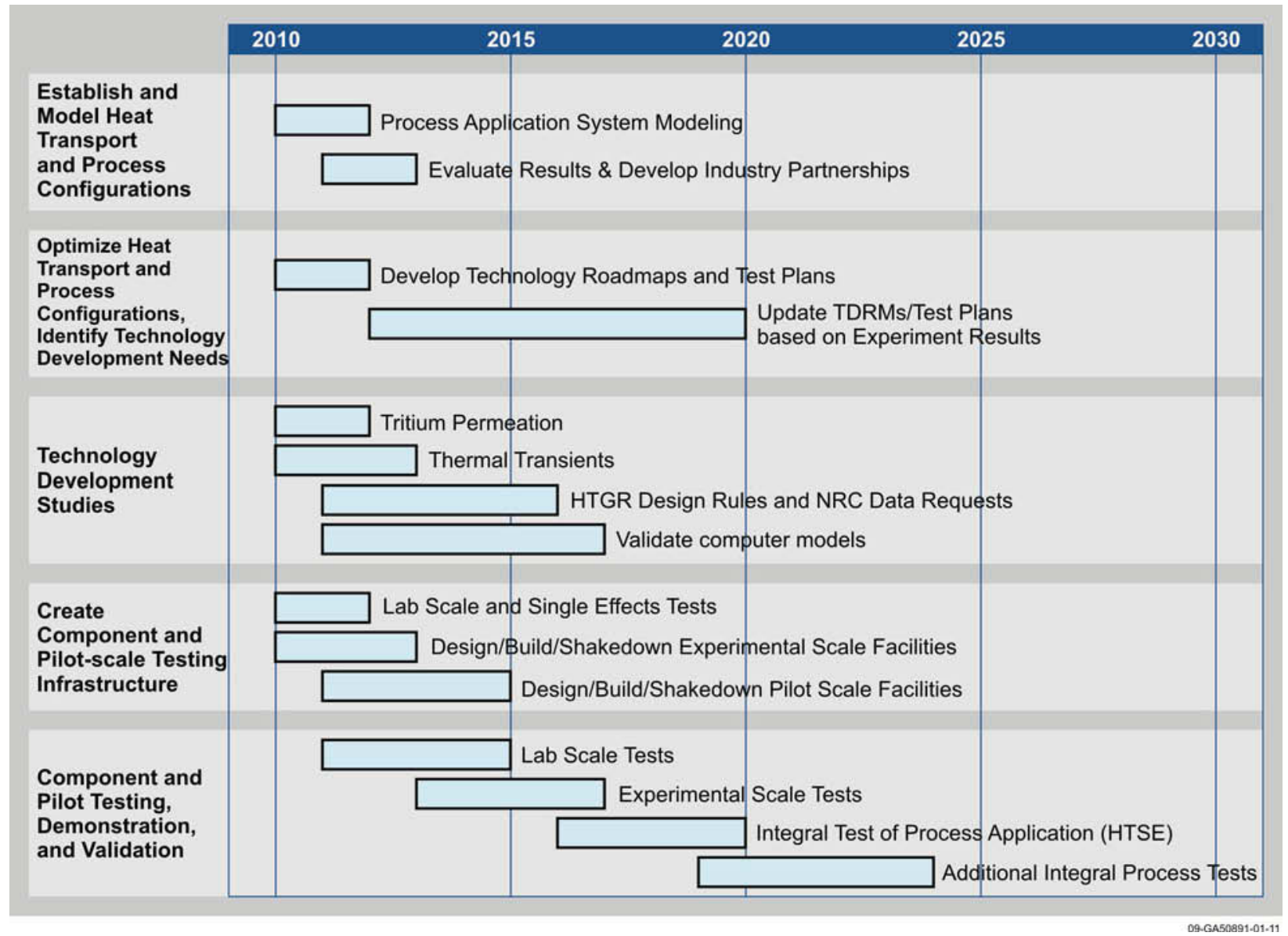

Figure 17. Schedule of heat transport activities. 


\subsubsection{Hydrogen Production}

Essentially carbon-free production of hydrogen can potentially play a key role in decreasing future petroleum imports, relieving the pressure on U.S. natural gas supplies, and reducing emissions from transportation fuels. Beyond the need for process heat, hydrogen is a vital feedstock in the production of ammonia, upgrading of low-grade petroleum and the production of synthetic transportation fuels. Major responsibility for development of hydrogen production and technologies rests with the DOE Office of Energy Efficiency and Renewable Energy (EERE). However, the use of nuclear energy to produce hydrogen imposes requirements and constraints different from other renewable energy sources and hydrogen generation technologies under development at the direction of EERE. These differences require technologies that are fitted to and integrated with the specific characteristics of nuclear systems, which are under the direction of DOE-NE.

High Temperature Electrolysis (HTE) is an efficient and modular method for producing hydrogen using nuclear energy. HTE was recently selected by DOE as the hydrogen generation technology of choice after it was recommended by an independent review team ${ }^{10}$ for use with the planned NGNP based on its maturity and ease of integration with nuclear systems. The review team also recommended that HTE R\&D: "(1) Refine the understanding of cell/stack degradation modes and mechanisms, and (2) Demonstrate pressurized cell/stack operation at a laboratory scale." The report also recommended evaluation of other alternative cell and stack designs. The path forward follows these recommendations and is organized into five major issues that must be addressed in the next 10 years and the strategy for resolving each issue.
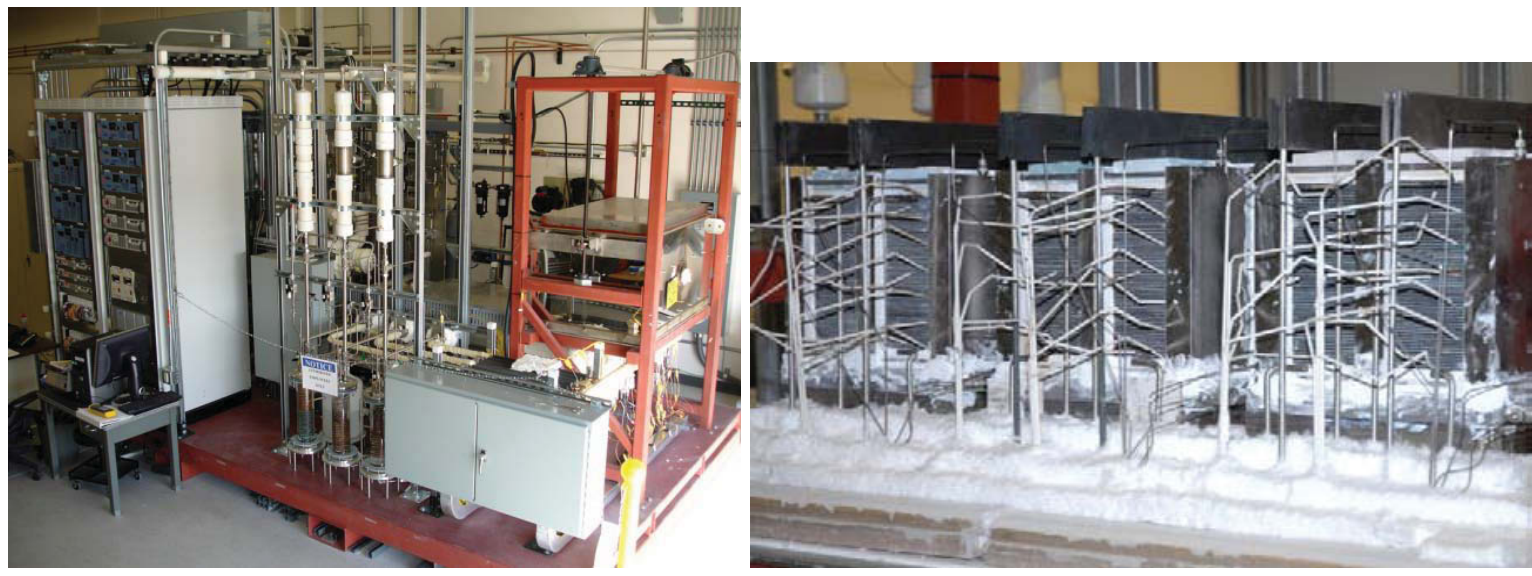

Figure 18. HTE integrated lab-scale experiment (left) and three electrolytic modules (right).

Improvements in Cell Performance - The performance of solid-oxide cells in the electrolytic mode must improve before this technology will be ready for commercial application. The strategy will be to focus on development of cells and stacks optimized for the electrolysis application. Based upon previous testing experience, the emphasis will shift from electrolyte-supported cell designs to advanced electrodeor metal-substrate-supported cell designs. The key variables in the cell designs will include cell architecture and the composition and fabrication methodology for all cell layers. In this context, an expansion of industrial collaboration is planned with a range of cell manufacturers and research institutions.

Larger Format Cells - Larger cells will be required in the large-scale nuclear production of hydrogen. The manufacture of larger format cells (up to $1 \mathrm{~m} \times 1 \mathrm{~m}$ ) will require innovative cell designs and fabrication methods. Electrode-supported and porous-metal-supported cells show great potential for large-format designs. The current state of the art for large-format cells is about $25 \times 25 \mathrm{~cm}$, with electrodesupported cells. Several large companies and research centers are developing porous-metal-supported 
cell designs for the fuel cell application, with the electrode and electrolyte layers deposited by thermal spray techniques. These cells have the potential to achieve very large sizes, up to $1 \times 1 \mathrm{~m}$. Work is planned with all potential cell providers in exploring the development of large-format cells for electrolysis, based on their respective technologies.

Pressurized Operation - Commercial HTE units will have to operate at elevated pressure in order to reduce manifold sizes and pumping power for insertion of the hydrogen into a pipeline or fuel synthesis/refining plant. Analyses and a design for a pressurized test stand will be developed. Elevatedpressure tests of a multi-cell stack will be conducted after the previous two issues are successfully addressed, probably in 2011. This work is required to validate the technology at the component level in a relevant operating environment.

Scientific Understanding of Electrolytic Operation - A deeper understanding of the implications of various cell and stack designs on details of cell, stack, and overall system performance is needed to complement the basic CFD and system analysis capability. These insights will be gained using advanced post-test examination methods for evaluating degradation mechanisms. The combined physical and numerical analysis will lead to optimized multi-cell and multi-stack manifolding and electrical interconnections.

Needs for Engineering Data for HTGR Design - HTE analyses and experiments must be coordinated with the needs for HTE-specific design data by the HTGR engineering teams. These design data needs for HTE have been identified and are being incorporated into a database. The specific parameters and their uncertainties identified will guide the design and operation of HTE experiments and their associated analyses. These data needs may need modification in the future to address the results of the ongoing engineering designs.

Hydrogen production milestones are:

- Establish collaborations in hydrogen production with DOE Offices of Energy Efficiency and Renewable Energy and Fossil Energy in 2010.

- Reduce rate of long-term electrolytic cell degradation to levels currently achieved by solid oxide fuel cells ( $2-4 \%$ per 1,000 hours) in 2013.

- Operate a high temperature electrolytic stack at expected commercial pressure, temperature, and current density in 2014.

- Partner with industry to develop the next generation of high temperature electrolysis cells for hydrogen production in 2015.

- Demonstrate integration of hydrogen production using nuclear energy with production of liquid transportation fuels in 2022 .

- Commercial operation of integrated hydrogen/liquid transportation fuel production plant in 2030. 
The schedule for the Hydrogen production research is shown in Figure 19.

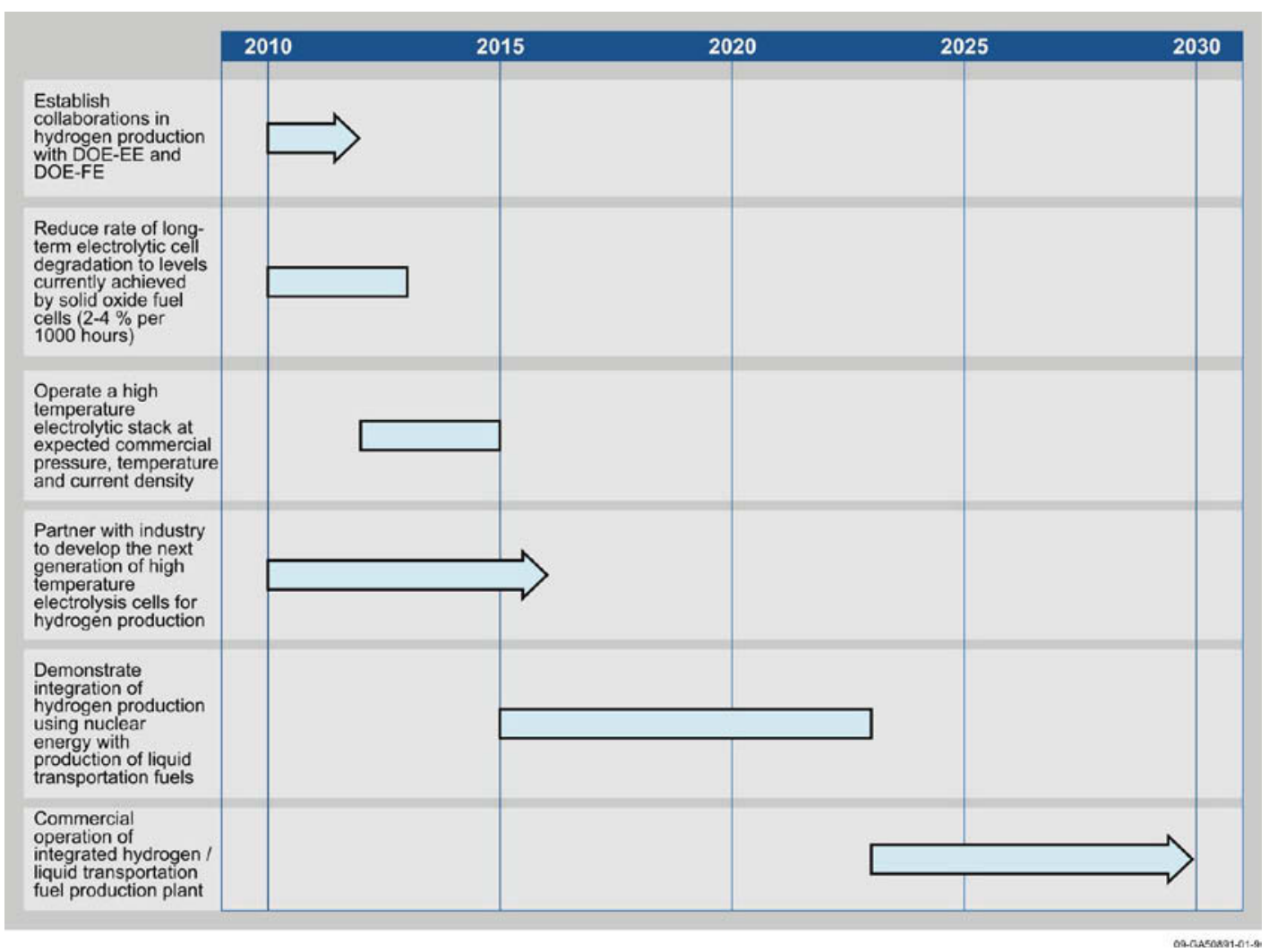

Figure 19. Hydrogen production research schedule.

\subsubsection{Feedstock Extraction and Processing for Hybrid Energy Applications}

Feedstock extraction and processing will utilize energy systems that combine nuclear energy with traditional processing technologies such as refining petroleum, processing and upgrading biomass, and producing bio-fuels and synthetic fuels. As was discussed in the case of hydrogen the use of a nuclear energy source to produce liquid fuels requires the integration and simultaneous control of both the nuclear reactor and the chemical plant. The unique characteristics of a nuclear energy source and the nuclear safety implications associated with this integration require the involvement of DOE-NE. These integrated systems will assist in reducing U.S. dependence on imported oil while shrinking the overall carbon footprint of these industries. Early process integration, capital cost studies, and life cycle analysis for conventional and nonconventional resource extraction and processing indicate high potential to costeffectively reduce the carbon emissions associated with fossil fuel use. ${ }^{11}$ Biomass pyrolysis or hydrothermal reforming can effectively use nuclear heat at temperatures around 850 to $900^{\circ} \mathrm{C}$. Increasing use of ligno-cellulosic biomass (e.g., wood waste and straw) will not only extend domestic resources and improve energy security but also present significant challenges related to the logistics of biomass feedstock supply. ${ }^{12}$

North American oil shale, oil sands, and heavy oil resources can be extracted and converted to transportation fuels and chemical feedstock with hydro-treatment. ${ }^{13}$ Using nuclear energy to extract and upgrade theses resources could be key to producing clean products. Conceptual design studies indicate that this is technically and economically feasible. ${ }^{14,15}$ 
Based on the vision and goals, the feedstock processing research pathway will attempt to establish an integrated platform across several DOE lines of research with activities in five focus areas:

- Using clean energy sources for processing biomass, low-grade and waste coal fines, carbonaceous waste materials, and algae --- finding ways to apply renewable and nuclear energy sources to perform energy intensive operations such as, oil sands, oil shale, and heavy oil production and feedstock drying, ash reduction, grinding or shredding, mechanical separation, and densification.

- Developing nuclear-driven processes to carry out feedstock conversion by steam reforming, supercritical water oxidation, pyrolysis, gasification, or solids retorting.

- Using nuclear heat applied for new heterogeneous catalysts, plasma reactors, and electrochemical reactors that chemically reduce, crack, or reform tars and oils produced by low temperature, possibly distributed gasifiers, or retorting operations that currently use low-grade heat to affect drying, pyrolysis, or mild gasification of feedstocks.

- Developing next-generation ${ }^{16}$ combustion methods for clean energy production technologies combined with nuclear heat for improved process sustainability and a lower carbon footprint. An example is the development of oxygen-fired process burners that obtain the hydrogen and oxygen from high temperature electrolysis.

- Developing distributed energy systems to produce unconventional fuels, stabilized biomass, and agricultural and other basic chemicals.

Each of these five R\&D focus areas will use integrated hybridized energy systems that effectively combine nuclear energy with other energy technologies including fossil, wind, and biomass. ${ }^{17}$

Feedstock extraction and processing milestones are:

- Establish collaboration in process heat and energy conversion with DOE-EE and DOE-FE in 2012.

- Demonstrate "clean-energy" source for feedstock size reduction, drying, and mild pyrolysis (torrefaction) in 2012.

- Develop/deploy new process technology that tailors feedstock foundations to downstream thermal processing equipment in 2012.

- Investigate process technology that utilizes low-grade heat for feedstock processing at small pilotscale facilities designed to demonstrate heat transfer and reaction kinetic phenomena in 2013.

- Develop/deploy process equipment using low-grade heat in collection depots in 2013.

- Perform a pilot-scale demonstration of feedstock processing concepts from 2015 to 2019.

- Demonstrate/deploy region-wide integrated energy networks for feedstock processing in collection depots from 2015 to 2019.

In the longer term,

- Partner with industry, DOE-EE and DOE-FE to site a renewable fossil/nuclear hybrid energy industrial park in 2020.

- Initiate operation of a public/private demonstration of a renewable/fossil/nuclear hybrid energy industrial park in 2030.

- Develop first commercial large scale hybrid energy industrial park by 2040 .

The schedule for the Feedstock Processing R\&D Pathway is shown in Figure 20. 


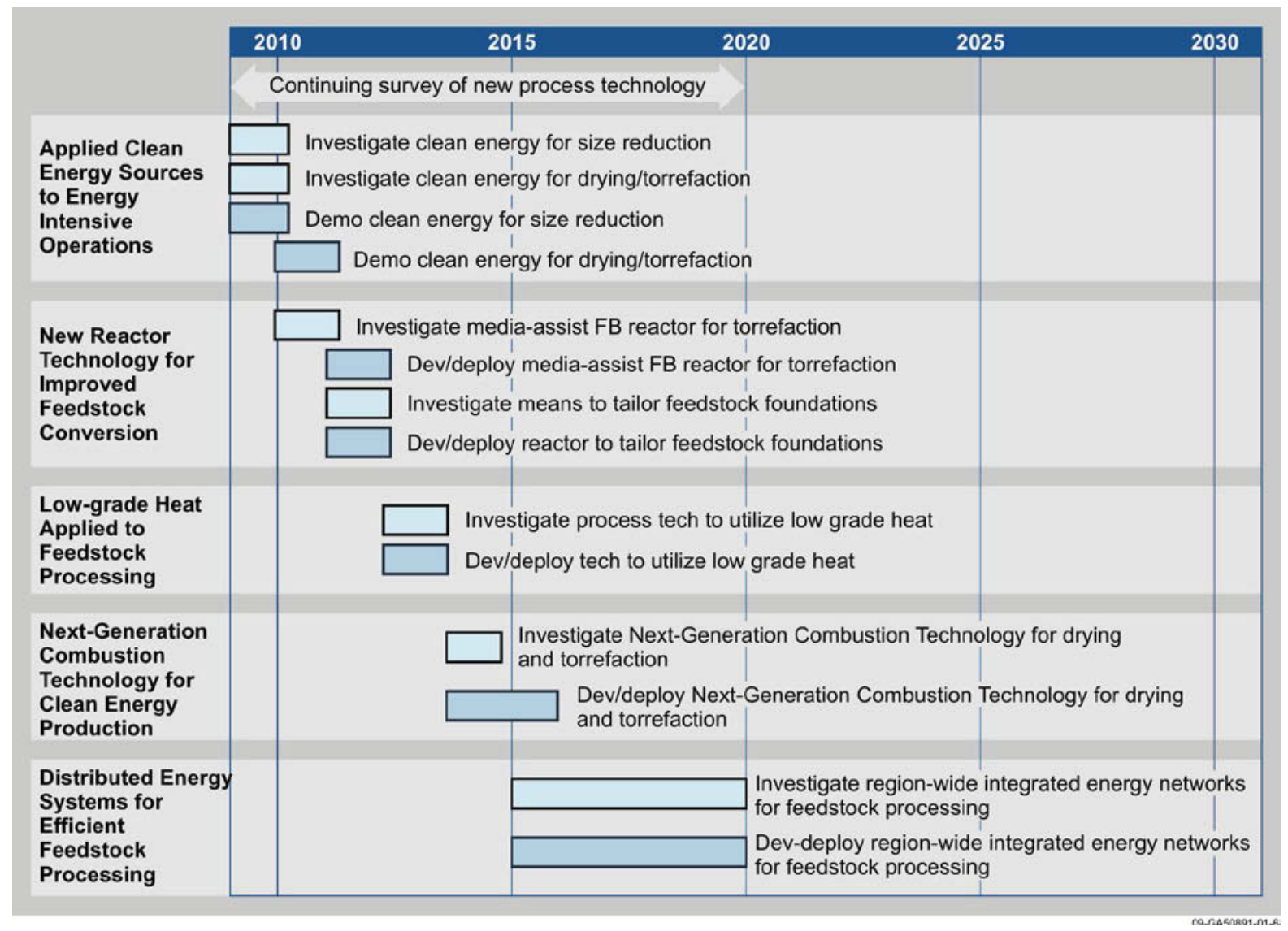

Figure 20. Feedstock processing R\&D pathway schedule.

\subsubsection{Byproduct Management}

Materials presently released to the environment as pollutants can often serve as the input materials for other processes. The research includes investigations into the use of carbon dioxide from combustion and the use of ammonia and hydrogen sulfide from gasifiers and wastewater treatment processes. Coelectrolysis, using nuclear energy to drive solid oxide electrolytic cells, can produce syngas (carbon monoxide and hydrogen) from carbon dioxide and steam for the synthesis of liquid fuels. Fugitive ammonia can be captured and converted to nitrate or urea fertilizers, while hydrogen sulfide can be converted into sulfur or sulfuric acid. Hybrid energy concepts such as flameless steam reforming and plasma dissociation using nuclear heat and electricity will be developed to improve process efficiency while avoiding secondary wastes. Cleanup and reuse of water co-produced with fossil resource recovery (e.g., oil sands, coal, coal-bed methane, mining water, etc.), and process and municipal wastewater treatment can use osmotic or evaporative processes to approach a zero discharge goal as shown in Figure 21.

Byproduct Management Milestones are:

- Conduct carbon dioxide recycle and reuse assessments taking into account thermodynamics, energy efficiency, costs relative to sequestration, etc. in 2012.

- Select industrial partners for cooperative research and development agreement development of zero discharge technologies in 2013. 
- Complete design and construction of pilot-scale test skid(s) for gas separations and recycle and process wastewater treatment in 2014.

- Initiate pilot scale zero discharge demonstrations with industrial partners in 2015.

The detailed schedule for byproduct management R\&D is shown in Figure 22.

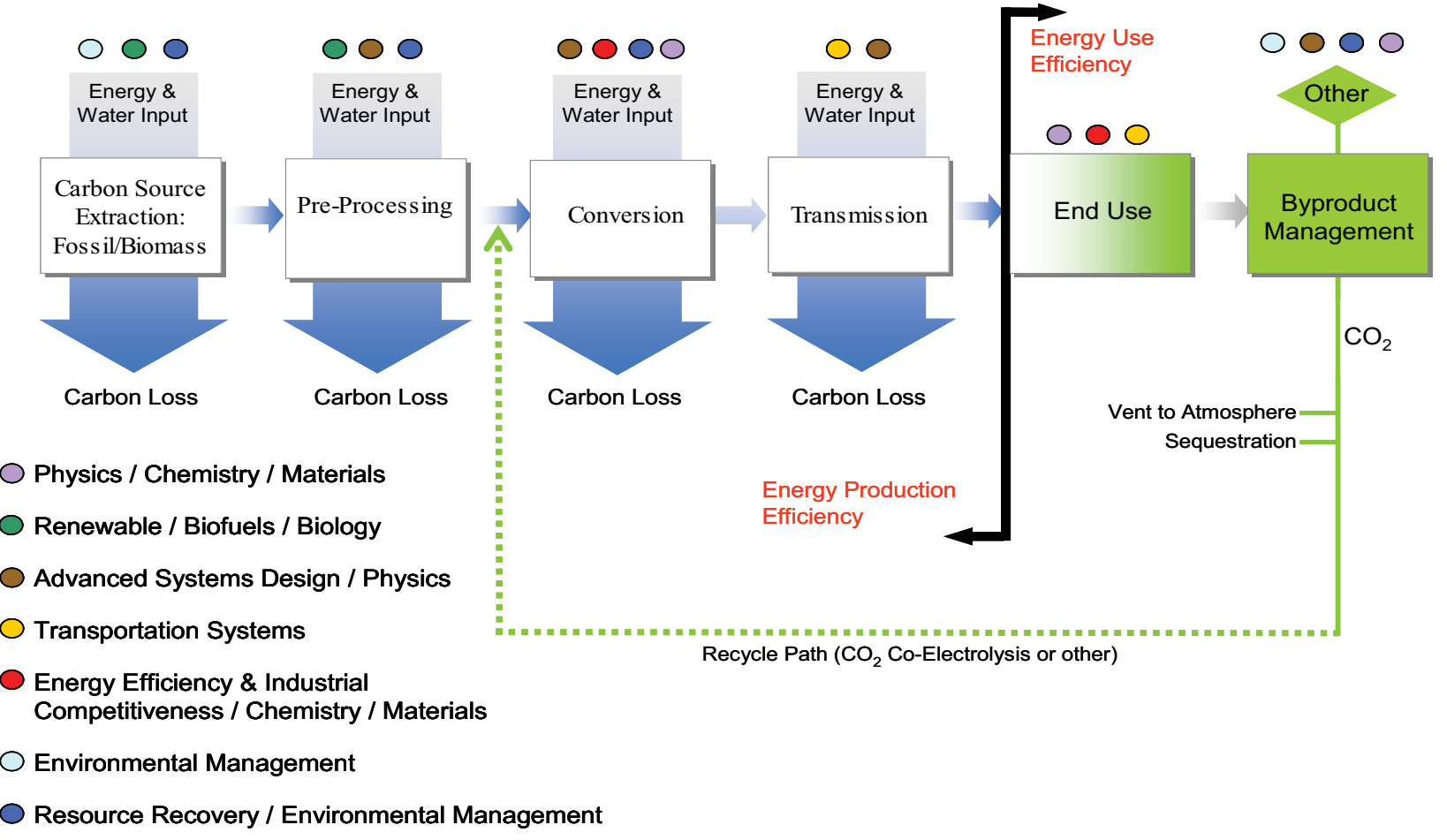

Figure 21. Total carbon management with carbon dioxide recycle using nuclear driven co-electrolysis.

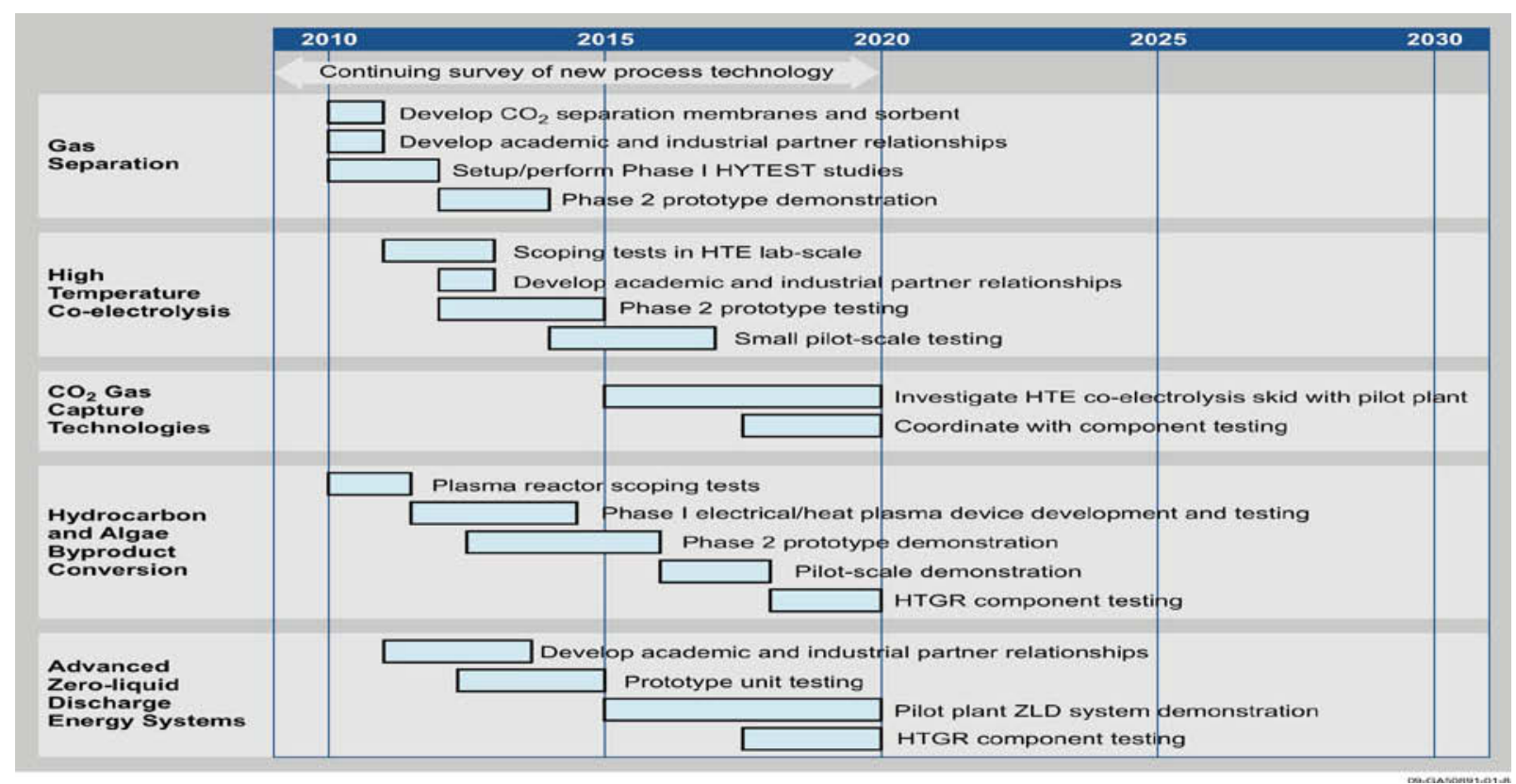

(Energy input in the figure can be provided by nuclear heat and electricity)

Figure 22. Byproduct management R\&D pathway schedule. 


\subsection{Regulatory Approach, System Economics, and the Business Case}

Lifecycle system analyses that consider various deployment options are needed to address overall system feasibility. Part of that assessment will consider traditional economic metrics but will need to include assessments against environmental metrics such as reductions in greenhouse gas emissions and the utilization of water, land, and carbon resources. Based on these assessments, more complete business models and regulatory approaches tailored to the nuclear technology and non-electricity application can be developed to facilitate the private sector investment decision-making process.

\subsubsection{Regulatory Approach and Required Innovation}

Overview of the Regulatory Approach - The NRC will license all commercial nuclear reactors, consistent with the Energy Reorganization Act of 1974. If new DOE reactors generate power for an electric utility system or demonstrate their suitability for subsequent use by the commercial power industry, then this Act assigns the responsibility for licensing them to the NRC. This section reviews the recommended regulatory approach and the high priority regulatory issues that must be resolved to enable the application of nuclear energy to industrial heat markets. Much of the approach describe here is based on the joint DOE and NRC report on the NGNP Licensing Strategy ${ }^{18}$. Licensing of the NGNP will serve as a test case for licensing of future advanced reactor concepts.

10 CFR Part 52 - The centerpiece of the licensing approach for a small modular reactor is a COL application submitted to NRC pursuant to 10 CFR 52, "Licenses, Certifications, and Approvals for Nuclear Power Plants," of the NRC regulations. Part 52 involves a one-step licensing process instead of the Part 50, two-step approach (construction permit and separate operating license). Successfully and efficiently implementing this approach requires that the project and NRC agree on a set of COL application development requirements and guidance documents tailored to small modular reactors. Successful implementation of this approach will be demonstrated with the submittal of the COL application for submittal of the COL application for the NGNP nuclear plant.

Adapting LWR Regulations - Given the limited regulatory experience with non-LWR technology as well as the potential deployment in nontraditional process heat applications, there is not an existing and complete body of regulations directly suited to non-LWR designs. Consequently, for a license application to be successfully prepared, reviewed, and approved, updated regulatory guidance (or an agreed framework) derived from the existing LWR regulations will have to be proposed and agreed upon to guide the approval of entire COL application preparation, review and approval process. While the initial set of non-LWR regulations would be created to support gas reactor technology and the NGNP, subsequent revisions should be made to address other reactor concepts and other reactor coolant technology, for both electric and non-electric applications. Engagement with the NRC is needed to reach agreement on the scope and development of new regulatory policies or to change existing regulatory policies that support the non-LWR designs so that the licensing strategy is successful.

Build on Previous Licensing Efforts Associated with Gas Reactors - During pre-application reviews of the Pebble Bed Modular Reactor (PBMR) in 2001 and 2002, Exelon proposed a licensing approach for the PBMR that made greater use of probabilistic risk information to establish the licensing basis for the PBMR. In 2007, the NRC staff published a report on the history of risk-informed licensing efforts and proposed the development of a proposed new reactor-licensing framework that relies more heavily on risk-informed performance-based concepts. This framework is documented in NUREG-1860, "Feasibility Study for a Risk-Informed and Performance-Based Regulatory Structure for Future Plant Licensing." The report includes a proposed set of new regulations as an example of what new regulations might look like. The NRC staff currently plans to further develop those draft requirements by gaining experience from licensing an advanced design. In addition, licensing efforts associated with Peach 
Bottom Unit 1 and the Fort St. Vrain Nuclear Generating Station, early gas-cooled reactors licensed by NRC under Part 50, will be reviewed for useful information and precedents.

Mixed Regulatory Jurisdiction - To date, nuclear power plants in the U.S. have not been licensed for industrial process applications. These applications present new and unique challenges to the licensing process. Programmatic interfaces between the process facility and the nuclear plant in areas such as security, emergency planning, fire protection, and design change control are expected to require integration and/or coordination to ensure that the nuclear operating license assumptions and conditions remain valid. In regard to licensing and regulatory oversight, the issue of defining an interface or boundary between the nuclear island and the remainder of the plant will require resolution with the regulators involved. As part of the NGNP licensing process, it is expected that resolution of this issue will be identified.

Implementation of a Risk-informed and Performance-based Licensing Approach - The licensing strategy for these smaller modular reactors should utilize a risk-informed and performance-based approach. The best approach to establish the licensing and safety basis for the small modular reactor is to develop a risk-informed and performance-based technical approach that adapts existing NRC LWR technical licensing requirements in establishing design-specific technical licensing requirements. This approach uses deterministic engineering judgment and analysis, complemented by probabilistic risk assessment (PRA) information and insights, to establish the licensing basis and requirements. This approach provides significant advantages in meeting the schedule for licensing a small modular reactor while providing consistency with Commission policy guidance on the use of probabilistic risk information and insights.

This strategy was recommended for the NGNP in the licensing strategy for the NGNP that was issued to Congress in August 2008, "Next Generation Nuclear Plant Licensing Strategy - A Report to Congress." In this document, the Secretary of Energy and the NRC jointly determined that the best option for licensing the NGNP prototype would be to use a risk-informed and performance-based technical approach that employs the use of deterministic judgment and analysis, complemented by NGNP-specific PRA information. Since this licensing approach has not been fully developed in an actual licensing application and approved by the NRC staff, there are questions regarding the integration of performance-based analysis and the deterministic analysis. These questions will be resolved in white paper submittals prior to COL application submittal, as part of the licensing process for the NGNP project.

Integrated Risk at Co-located Sites - It is anticipated that small reactors co-located at industrial facilities will utilize multiple modules. While a demonstration plant (like NGNP) is just a single reactor module, the demonstration plant is a model for follow-on commercial plants some of which may include more than one reactor module. Therefore, it is necessary to address the issue of integrated risk associated with multiple modules. In evaluating risk assessments for compliance with the NRC's Safety Goals, the NRC staff's current practice for large reactors has been to assess risk on an individual reactor basis. The use of modular designs could result in a large number of reactors on a single site. It is also recognized that new reactors may be constructed on new sites or existing sites (sites that already have one or more operating reactors). Therefore, the issue of integrated risk applies to both design and siting reviews. Three options to address this issue are described in SECY-05-0130, "Policy Issues Related to New Plant Licensing and Status of the Technology-Neutral Framework for New Plant Licensing." These options are: (1) No consideration of integrated risk, (2) quantification of integrated risk at the site only from new reactors (the integrated risk would not consider existing reactors), and (3) quantification of integrated site risk for all reactors (new and existing) at that site.

Understanding of Source Term - HTGR and other smaller advanced reactors are expected to be able to demonstrate accident source terms for use in plant primary system and containment barrier design that are lower than source terms currently used for large LWRs. For example, HTGR fuel is expected to perform without significant failure during anticipated operational events, design basis accidents, and even 
some beyond design basis accidents. Since the fuel is the main barrier to fission product release in an HTGR, the NRC staff must have sufficient knowledge and information regarding the HTGR fuel to ensure adequate regulatory oversight and controls and to ensure an adequate basis for the HTGR source term.

Lessons Learned to Support Risk-Based Regulations - Once the HTGR technology is demonstrated through successful operation and testing of the NGNP prototype, and a quality PRA, including data, becomes available, greater emphasis on design-specific PRA to establish the licensing basis and requirements will be a more viable option for licensing a commercial version of the HTGR reactor for the broad range of end user applications. This licensing approach would adapt the existing LWR technical requirements to address the acceptability of the HTGR design and to establish the HTGR-unique requirements that are not addressed by existing LWR requirements and guidance. These efforts will help shape future development of a new Part 53 regulation.

Pre-licensing White Papers - Prior to submittal of the COL, it is important to establish early approaches to the resolution of issues that can significantly impact the preparation of acceptable COL applications, subsequent application review schedules, and ultimate deployment of the demonstration plant. In addition to the topics addressed above, the project will identify a listing of licensing issues that are considered to be of highest priority, and will therefore be a focus of the project team in the early stages of the project.

Interactions with NRC Staff - Frequent, focused, and coordinated interactions between the NRC Staff and the small modular reactor project team will be critical to the success of the project.

Licensing Milestones are:

- Partner with industry to demonstrate the licensing and permitting process for a reactor configured for process heat applications by 2011 .

- Resolution of the mixed regulatory issue in 2014, around the time of NGNP COL application submittal.

- Resolution of the integrated risks at co-located sites issues in 2018 around the time that a COL application for a multi-module plant is submitted.

- Compile lessons learned from the NGNP COL licensing around 2020, one to two years after COL issuance.

\subsubsection{System Economics and the Business Case}

Integrating nuclear energy into processes beyond electricity will significantly enhance our nation's energy security through more effective utilization our country's carbon-based resources while simultaneously providing economic stability and growth and in an environmentally sustainable manner. These highly integrated nuclear and non-nuclear processes are very different from the present U.S. industrial infrastructure because hybrid energy systems require optimization of environmental stability, economic stability, and resource security (See Figure 23). It will be necessary to develop and analyze a variety of business models that integrate nuclear energy with non-electric industrial applications in order to establish a sound economic basis for these hybrid energy systems. The goal is to provide technically rigorous and defensible energy security assessments that include technical performance, economic analysis, environmental attributes, resource utilization estimates, and capability for national security enhancement. Small modular reactors are uniquely suited to hybrid energy applications because of their small size. Of the SMR designs currently under consideration, HTGRs are one of the most viable options because of their inherent safety characteristics which allows collocation with industrial processes. 
Value analysis techniques will be developed and implemented to provide decision makers with guidance regarding the value of investing in nuclear energy driven hybrid systems and to help prioritize $\mathrm{R} \& \mathrm{D}$ pathways based on technology return on investment.

This R\&D pathway will focus on the economic analysis to establish a credible business case for nuclear-driven hybrid energy systems.

Systems Stability Analyses - Steady-state and dynamic models will be used to analyze system compatibility and stability. For hybrid systems, the potential size disparity between components (nuclear reactor vs. small wind farm) requires engineering and economic decisions to assure the systems will work together in a variety of conditions.

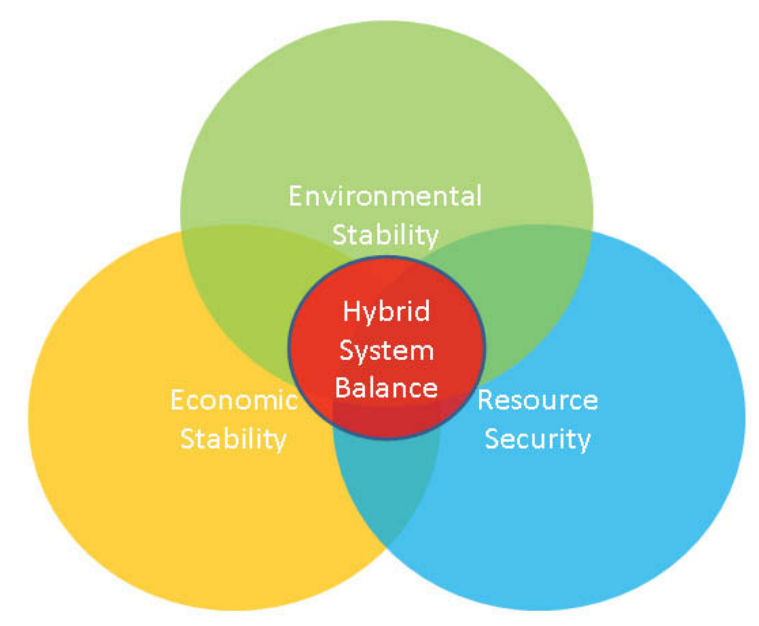

Environmental Attribute Analyses - A significant result of the stability analysis/design effort will involve the tracking of all byproducts that impact the environment, including greenhouse gasses, radioactive waste, wastewater discharges, overall water usage, regulated air pollutants, and other gas, liquid, and solid discharges.

Deployment and Macro Economic Benefit Analyses - The implementation of integrated nuclear and industrial processes as well as hybrid energy parks will be analyzed to determine the overall economic benefits as a function of deployment scenario, product mix, market externalities, and environmental attributes.

System economics and the business case milestones are:

- Complete an analysis and publish a report concerning the systems stability and environmental performance of two reference nuclear hybrid energy systems designs, including both HTGR and LWR technology and emphasizing transportation fuels production in 2014.

- Complete detailed analysis of potential business models to accommodate the reference hybrid energy system design in 2016.

\section{Program Management}

More than one program, each with its own associated program management structure, may be needed to execute all of the workscope associated with the R\&D pathways in this imperative. In this section, the program management structure for the NGNP project is presented as a current example because it is the largest single program to date in this imperative.

The NGNP is the lead program for implementing Imperative 3. The NGNP project partners with industry to sponsor R\&D, design, and licensing of gas cooled reactor technology for use in industrial processes. The goal of the program is to complete construction of a demonstration reactor in 2021 . In addition to gas-cooled reactors, the DOE recognizes the potential for other reactor technologies to integrate into industrial processes. The DOE is in the process of developing new programs that will address the development and commercialization of these reactors including small light water reactors, sodium cooled and salt cooled reactors. 
Details of NGNP project management are available in the Next Generation Nuclear Plant Report to Congress, March 2010.

\subsection{Organization Structure}

The Office of Nuclear Energy through the Office of Gas Cooled Reactor Technology manages the NGNP project. The INL works with DOE to integrate the efforts of universities, industry, and other national laboratories on behalf of the DOE. The DOE is in the process of formally partnering directly with industry to conduct the conceptual design of the NGNP. Conceptual design awards will be administered through the DOE's Idaho Operations Office.

\subsection{Roles, Responsibilities, Accountabilities, and Authorities}

\subsubsection{Department of Energy - Office of Nuclear Energy}

DOE is responsible for the Federal government's investments in nuclear power research, development, demonstration, and incentive programs, which all further the nation's supply of clean, dependable nuclear-generated electricity. The NGNP R\&D program conducts research that will enable the design and licensing of gas-cooled reactor technology for industrial use as a source of heat and electricity. The DOE Office of Gas Cooled Reactor Technology directs the NGNP project, establishes policy, and approves scope, budget, and schedule for the program through the DOE NGNP project Manager. The DOE NGNP project Manager is assisted with program management and oversight by DOE-ID and by the INL NGNP Project Director.

The essential programmatic DOE functions include, but are not limited to, the following:

- Establish program policy and issue program guidance,

- Conduct program planning and develop budgets,

- Establish requirements, standards, and procedures,

- Establish performance measures and evaluate progress,

- Prepare and administer procurements and offerings of financial assistance, and

- Collaborate with the U.S. NRC to develop and implement a licensing strategy for NGNP.

\subsubsection{Department of Energy - Idaho Operations Office}

DOE-ID is responsible for day-to-day monitoring of the performance of the INL. In addition, DOE-ID is the Office responsible for all federal contracting for the NGNP project. DOE-ID applies its unique expertise in project management, quality assurance, and environmental compliance to the NGNP project.

\subsubsection{National Laboratories}

INL is the lead lab for the NGNP project. Planning and execution of the R\&D and supporting activities required to design and license gas cooled reactor technology in the U.S. is the responsibility of the INL NGNP Project Director and the INL Technology Development Office. INL also coordinates and monitors the activities of other DOE National Laboratories that contribute to the program. Principal contributors include the Oak Ridge National Laboratory and the Argonne National Laboratory. INL also monitors R\&D conducted by U.S. universities for the program.

INL performs the following functions: 
- Maintaining all technical and program planning documents,

- Developing annual work packages to manage scope and cost,

- Developing and implementing the project execution plan,

- Monitoring authorized project work,

- Coordinating weekly/monthly status meetings,

- Coordinating periodic technical review meetings,

- Providing formal status reporting, and

- Maintaining baseline change control.

\subsubsection{Project Monitoring and Evaluation}

DOE uses a variety of methods to provide oversight including monitoring of earned value project cost and schedule reports, monthly and weekly meetings, and annual project reviews.

Project Reviews. DOE conducts annual project progress review meetings with the project participants. During these project review meetings, project activities, schedule progress, and cost are discussed in detail. Status of deliverables, funding, or schedule concerns and potential changes in scope are discussed. On an annual basis, DOE staff reviews the work scope, budget requirements, schedule, deliverables, and milestones for the subsequent budget periods as part of the approval of project work packages for the coming year. Review of these work packages often requires telephone and face-to-face meetings with project participants to fully understand the future planned work.

Periodic Project Status Meetings and Conference Calls. The Office of Gas Cooled Reactor Technology has weekly telephone conference meetings with senior project management at the INL and DOE-ID to discuss successes, failures, and upcoming activities important to the project. In addition, DOE and all project participants meet monthly to discuss cost and schedule earned value performance. DOE also holds bi-weekly conference calls with the U.S. NRC on the status of licensing activities. In addition to these formally established meetings, daily calls are common between DOE staff and project participants.

Monthly Progress and Earned Value Reporting. DOE personnel review and evaluate project monthly progress reports for the project task and activity progress, accomplishment of deliverables, and budget and cost status. Because of the size, cost, and complexity of the NGNP project, earned value is reported on a monthly basis. This earned value reporting provides project participants and DOE staff with a monthly snapshot of overall project cost and schedule performance against the project baseline.

\subsection{Interfaces}

Established interfaces include the NRC, industry, universities, and Nuclear Energy Advisory Committee (NEAC). As the implementation of Imperative 3 matures, other groups will likely be included.

- Department of Energy Office of Energy Efficiency and Renewable Energy - The DOE-EE is responsible for developing technologies for the harvesting and utilization of biomass and has a large program in the production and use of hydrogen. Small scale collaboration between DOE$\mathrm{EE}$ and DOE-NE in these areas has been ongoing for five years.

- Department of Energy Office of Fossil Energy - The DOE-FE is responsible for ensuring that we can continue to rely on clean, affordable energy from our traditional fuel resources. Future 
collaboration between DOE-FE and DOE-NE is planned to aid in the development of clean hybrid energy industrial parks and the use of traditional fuel resources with minimum greenhouse gas emissions.

- U.S. Nuclear Regulatory Commission - The NRC is responsible for licensing commercial nuclear reactors in the U.S. DOE works with NRC to establish a regulatory framework for gascooled reactors.

- Industry Partners - DOE is working to form partnerships with industry to conduct the conceptual design of the NGNP. To date, all of the applicable reactor vendors interested in gascooled reactor technology have worked with the Department on pre-conceptual designs and on establishing R\&D needs.

- Nuclear Energy Advisory Committee - The Energy Policy Act of 2005 created a requirement for several reviews by the NEAC of the NGNP project. NEAC will conduct a major review of the NGNP beginning in September of 2010.

- University Partners - Universities participate in the program in at least two ways: (1) through the Nuclear Energy University Program and (2) with direct contracts from the INL, DOE, or NRC.

- International Entities - DOE-NE collaborates with foreign industry, regulators and academia to further advance gas-cooled reactor technology. DOE-NE is also an active participant in the Generation IV International Forum among other international groups. 


\section{REFERENCES}

1. Energy Information Agency, an Updated Annual Energy Outlook 2009 Reference Case, Table A11.

2. NETL, Life-Cycle Analysis of Greenhouse Gas Emissions for Hydrogen Fuel Production in the United States from LNG and Coal DOE/NETL-2006/1227 November 2005, page 13.

3. MPR Associates Inc., "Survey of HTGR Process Energy Applications," May 2, 2008, MPR-3181.

4. See www.nextgenerationnuclearplant.com.

5. David Petti, Richard Hobbins, James Kendall, and John Saurwein, Technical Program Plan for the Advanced Gas Reactor Fuel Development and Qualification Program, INL/EXT-05-00465, Revision 1, August 2005.

6. W. Windes, T. Burchell, R. Bratton, Graphite Technology Development Plan, PLN-2497, Rev 0, October 2007.

7. Next Generation Nuclear Plant Intermediate Heat Exchanger Materials Research and Development Plan, Idaho National Laboratory PLN-2804, April 2008.

8. R. N. Wright, J. K. Wright, T. L. Sham, R. Nanstad, and W. Ren, Next Generation Nuclear Plant Reactor Pressure Vessel Materials Research and Development Plan, Idaho National Laboratory PLN2803, April 2008.

9. R. Schultz et al., Next Generation Nuclear Plant Methods Technical Program Plan Idaho National Laboratory, PLN-2498, Rev 0, October 2007.

10. R.Varrin et al., NGNP Hydrogen Technology Down-Selection Results of the Independent Review Team (IRT) Evaluation, R-6917-00-01, Revision 0, July 31, 2009.

11. INL/EXT-09-16942, Revision 0, "Integration of High- Temperature Gas-Cooled Reactors into Industrial Process Applications", September 2009.

12. Hess, J.R., Wright, C.T., Kenney, K.L., Searcy, E.M. "Uniform-Format Solid Feedstock Supply System: A Commodity-Scale Design to Produce an Infrastructure-Compatible Bulk Solid from Lignocellulosic Biomass - Executive Summary.” Idaho National Laboratory: Biofuels and Renewable Energy. April (2009). 30 July 2009.(www.inl.gov/bioenergy/uniform-feedstock).

13. A Technical, Economical, and Legal Assessment of North America Heavy Oil, Oil Sands, and Oil Shale Resources," prepared for the U.S. DOE by the Utah Heavy Oil Program, September 2007.

14. INL/EXT-09-16942, Revision 0, "Integration of High- Temperature Gas-Cooled Reactors into Industrial Process Applications", September, 2009.

15. Charles W. Forsberg, "Sustainability by Combining Nuclear, Fossil, and Renewable Energy Sources," Progress in Nuclear Energy, 2008.

16. An example of a "Next Generation" combustion technology is the "FutureGen" DOE program.

17. R. S. Cherry and R. A. Wood, "Use of a Nuclear High-Temperature Gas Reactor in a Coal-to-Liquids Process," Idaho National Laboratory, August (2006).

18. Next Generation Nuclear Plant Strategy-a Report to Congress, August 2008. 